\title{
Mercado laboral y distribución del ingreso en Colombia en los años noventa
}

\section{José Antonio Ocampo,}

Secretario Ejecutivo de la CEPAL jaocampo@eclac.cl

\section{Fabio Sánchez}

Profesor-Investigador,

Facultad de Economía,

Universidad de los Andes, Bogotá fasanche@uniandes.edu.co

\section{Camilo Ernesto Tovar}

Asesor del Secretario

Ejecutivo de la CEPAL

cetovar@students.wisc.edu
Este artículo analiza el comportamiento y los cambios del mercado laboral en Colombia en la década de los noventa. Resume, en primer término, las reformas y hace una breve reseña de la evolución macroeconómica y de los cambios en la estructura productiva durante los años noventa. A partir de la información disponible en las encuestas de hogares, analiza posteriormente la dinámica laboral, por sectores económicos, nivel educativo y posición ocupacional. Después de resumir los últimos adelantos de la investigación sobre distribución del ingreso para el caso colombiano, muestra los resultados de los ejercicios de simulación, cuyo objetivo es determinar los efectos de los cambios observados en las condiciones del mercado laboral (estructura sectorial del empleo, salarios relativos, desempleo y participación laboral) sobre la distribución del ingreso y la pobreza, tanto para el agregado nacional como para los sectores urbano y rural. Se concluye que la capacidad de la economía para generar empleo se ha deteriorado notablemente. Este deterioro ha afectado sobre todo a la mano de obra menos calificada. 


\section{I}

\section{Introducción}

$\mathrm{Al}$ igual que otros países latinoamericanos, Colombia ha estado inmersa en los años noventa en un intenso proceso de reformas estructurales. En el frente externo, este proceso ha tenido elementos comunes con otras experiencias regionales - la reforma comercial y la apertura a la inversión extranjera directa-, pero también matices diferentes, en especial el mantenimiento de un manejo activo del endeudamiento externo. Ha estado acompañado de una reforma laboral moderada y de una más ambiciosa del sistema de seguridad social. Esta última forma parte de un proceso más amplio de apertura al sector privado de áreas tradicionalmente reservadas al Estado. El otorgamiento de autonomía al Banco de la República (banco central) y una serie de reformas orientadas a acrecentar la competencia entre intermediarios financieros y a mejorar la regulación y supervisión prudencial son los elementos más destacados en el campo monetario y financiero. La diferencia más importante en relación con los patrones regionales ha sido, sin embargo, la combinación de estos procesos de liberalización de la economía con un crecimiento significativo del tamaño del sector público, orientado a ampliar la provisión de servicios sociales. Pese a un incremento también significativo de los ingresos públicos, esta última tendencia se tradujo en un deterioro de la situación fiscal, y demuestra la dificultad que ha enfrentado el Estado colombiano para conciliar la liberalización de la economía con una política social más activa.

\section{II}

\section{Las reformas}

El proceso de reformas estructurales, que se ha conocido en Colombia como "apertura económica", se ini-

\footnotetext{
$\square$ Este trabajo fue elaborado para el proyecto PNUD-CEPAL-BID sobre "Liberalización de la balanza de pagos: efectos sobre el empleo, la distribución, la pobreza y el crecimiento". La sección V se escribió en autoría con Jairo Núñez. Agradecemos los comentarios que Jaime Aristy, Samuel Morley, Roberto Paes de Barros, Juan Carlos Ramírez, Lance Taylor, Rob Vos y otros participantes en el proyecto hicieron a versiones anteriores de este texto. Se agradece también el trabajo de asistencia de Piedad Urdinola.
}

En términos de la actividad productiva, la economía creció en los noventa a tasas moderadas, con mayor inestabilidad que en el pasado, particularmente en el comportamiento de la demanda agregada, y con un descenso gradual de las tasas de inflación. A lo largo del proceso se han debilitado marcadamente los sectores más expuestos a la competencia externa y se ha deteriorado el mercado laboral. Este último ha experimentado un proceso de recomposición, acompañado de menor generación de empleo, especialmente en los sectores productivos más abiertos a la competencia internacional, como la agricultura y la industria manufacturera. La recomposición del mercado laboral se ha manifestado en la expulsión de mano de obra con un bajo nivel de educación que no ha sido compensada completamente con una mayor generación de empleo de trabajadores con más instrucción. Esto sugiere que el cambio técnico que ha tenido lugar desde comienzos de los noventa se ha orientado hacia procesos de uso más intensivo de mano de obra con mayor escolaridad, al tiempo que ha ahorrado mano de obra de todos los grados de calificación. Los cambios experimentados en el mercado del trabajo han tenido efectos adversos sobre la distribución del ingreso a nivel urbano, que han predominado en el conjunto del país sobre los efectos favorables de esos cambios en las zonas rurales. Estas últimas se han visto afectadas fundamentalmente por un choque adverso de los términos de intercambio rural-urbanos y la crisis consiguiente de la agricultura comercial.

ció a fines de la Administración Barco y recibió su mayor impulso durante la Administración Gaviria (19901994). Con algunos matices, la Administración Samper (1994-1998) profundizó las reformas y la actual (Pastrana, 1998-2002) prosigue con ellas. El principal elemento de este proceso fue la liberalización de las transacciones externas, es decir, de los regímenes comercial, cambiario y de inversión extranjera directa. Estas reformas estuvieron acompañadas no solamente de crecimiento económico, sino también de un cam- 
bio en la estructura y una redefinición de las funciones del sector público, todo ello enmarcado en una reforma profunda del Estado, a partir de la expedición de una nueva carta política en 1991. A estos procesos debe agregarse una moderada flexibilización del régimen laboral en 1990, y una reforma más ambiciosa del sistema de seguridad social, en 1993 (Ocampo, 1998).

\section{La liberalización de las transacciones extemas}

La liberalización comercial ha tenido dos componentes básicos: la liberación de las importaciones y la subscripción de un amplio conjunto de acuerdos de integración y libre comercio. Tanto el programa de liberación que puso en marcha la administración Barco en febrero de 1990 como el más ambicioso anunciado pocos meses después por la administración Gaviria proponían una reducción gradual de los aranceles (durante cinco y tres años, respectivamente), después de un rápido desmantelamiento de las restricciones cuantitativas a las importaciones. No obstante, una serie de complicaciones macroeconómicas llevaron a las autoridades a acelerar el proceso de liberación, que culminó en agosto de 1991. En este período de año y medio se eliminaron virtualmente los controles directos a las importaciones, se redujo el arancel promedio del $44 \%$ al $12 \%$, y se recortaron los incentivos a las exportaciones, del 19\% en 1990 al $6 \%$ en 1993. Con el objetivo de atenuar los efectos de las fluctuaciones de los precios internacionales, se adoptó un sistema de bandas de precios (aranceles variables) para la agricultura. Este proceso estuvo acompañado del diseño de estatutos de competencia desleal y de salvaguardias que, en general, fueron utilizados en forma moderada en los años siguientes.

Por su parte, la intensificación del proceso de integración comercial fue el resultado de decisiones adoptadas en 1989, cuando los presidentes del Grupo Andino - transformado posteriormente en Comunidad Andina- acordaron revitalizar, profundizar y reorientar el proceso de integración subregional. Sucesivas reuniones condujeron a acordar, en 1991, el establecimiento de una zona de libre comercio que debía entrar en vigor en 1992. No obstante, en ese año sólo fue posible establecer un área de libre comercio con Venezuela y Bolivia, a la cual se incorporó Ecuador un año más tarde. A fines de 1994 se adoptó, con algunas excepciones, un arancel externo común, que en la práctica se aplica únicamente a Colombia, Venezuela y, con amplias excepciones, a Ecuador. Este proceso fue complementado por la subscripción del acuerdo de libre comercio con Chile en 1993 y México (el Grupo de los Tres, que también incluye a Venezuela) en 1994, y el inicio de las negociaciones Comunidad AndinaMercosur en años posteriores, entre otros procesos.

Los principales componentes de la liberalización de la cuenta de capitales fueron la reforma cambiaria y la apertura a la inversión extranjera directa (IED). Esta última se había iniciado a fines de los ochenta, pero se completó en 1990 y 1991, cuando se eliminaron todas las restricciones a la IED, excepto en áreas de seguridad, desechos tóxicos e inversiones mineras de gran tamaño. Simultáneamente, se liberalizó el régimen de inversiones colombianas en el exterior. En los años siguientes se comenzaron a suscribir acuerdos de protección mutua a la inversión extranjera.

Por su parte, la reforma cambiaria de 1991 descentralizó el manejo de las transacciones en moneda extranjera, al autorizar a los intermediarios su manejo sin controles previos por parte del Banco de la República. No obstante, buena parte de las transacciones continuaron siendo reguladas, incluyendo la obligación de canalizarlas a través de intermediarios financieros legalmente autorizados a operar en el mercado. Para las transacciones de capital se mantuvo un estricto control sobre el uso final de estos préstamos (inversión y operaciones de comercio exterior). Sólo en febrero de 1992 se permitió, por primera vez, contratar créditos de corto plazo en el exterior para financiar capital de trabajo. La reforma cambiaria de septiembre de 1993 autorizó a los intermediarios financieros a realizar préstamos en moneda extranjera a empresas nacionales, sin importar el uso de dichos créditos, al tiempo que sustituyó el anterior sistema de regulación por uno basado en la obligación de los deudores en moneda extranjera de mantener un depósito o encaje en el Banco de la República. Con ello se pretendía controlar la magnitud y composición de los flujos de capital. ${ }^{1}$ El plazo de los créditos a partir del cual el encaje se hacía efectivo y el monto de éste se hicieron más restrictivos en 1994, se suavizaron en 1996 y se hicieron nuevamente más restrictivos en 1997. En mayo de este último año se introdujo un sistema más simple de control al endeudamiento externo, más similar al utilizado por Chile a lo largo de la década de los noventa, que obliga a todos los préstamos a hacer un depósito. La magnitud del impuesto implícito de este régimen de capitales fue consistentemente superior al del régimen

\footnotetext{
${ }^{1}$ Para un análisis detallado de las regulaciones a los flujos de capital, así como de su efectividad, en la década de los noventa, véanse Ocampo y Tovar (1999) y Villar y Rincón (2000).
} 
chileno durante los años de abundancia de capitales externos (un promedio de $13.6 \%$ y $6.4 \%$ en $1994-1998$ para créditos de 12 y 36 meses, respectivamente). ${ }^{2}$ Durante la crisis de fines de la década la magnitud de este depósito se redujo gradualmente, hasta su eliminación a comienzos del año 2000.

\section{Crecimiento, cambio estructural y redefinición de las funciones del Estado}

La Constitución de 1991 y otras decisiones políticas adoptadas a lo largo de la década tuvieron un impacto significativo sobre la estructura del Estado, que alteró la dinámica de las finanzas públicas. La conjunción de esta dinámica con el proceso de reformas estructurales es, como lo señalamos en la introducción, una peculiaridad del caso colombiano en el contexto latinoamericano. Su singularidad radica en que el proceso de apertura y desregulación de la economía ha estado acompañado de un aumento en el tamaño del Estado, que pasó del 30\% del PIB en 1990 a un 38\% a fines de la década de los noventa.

Las reformas con mayor incidencia fiscal fueron el incremento de las transferencias a los departamentos y a los municipios para financiar una mayor inversión social y la ampliación de la cobertura de la seguridad social. Se ha estimado que la Constitución de 1991 y las leyes que la desarrollaron (especialmente la ley 60 de 1993, que puso en marcha el nuevo sistema de transferencias, y la ley 100 de 1993, que creó el nuevo sistema de seguridad social) asignaron un gasto permanente del gobierno nacional equivalente a poco más del 4\% del PIB (Ocampo, 1997). Esta es la fuente principal del aumento total del gasto del gobierno central, excluyendo intereses. Pese a su privatización parcial, la reforma de la seguridad social se reflejó igualmente en un aumento paralelo de las prestaciones otorgadas por las entidades públicas correspondientes.

La rápida expansión del gasto se compensó en gran medida con mayores ingresos tributarios, en particular con mayores impuestos del gobierno central, por el aumento de las cotizaciones de la seguridad social, y en menor medida, por impuestos municipales. En efecto, el cambio en la estructura tributaria originado

\footnotetext{
2 Cabe agregar que en los primeros meses de 1997 hubo también un corto episodio de tributación explícita a los flujos de capital, que fue declarado inexequible por la Corte Constitucional, debido al procedimiento utilizado para decretarlo (la figura constitucional de la "emergencia económica").
}

por la liberalización comercial, que introdujo una menor dependencia de ingresos externos, fue compensado por sucesivas reformas tributarias $(1990,1992$, 1995, 1997, 1998 y una en curso en el 2000), que sirvieron para financiar, aunque sólo parcialmente, el incremento de gastos. Desde mediados de la década, el déficit fiscal, particularmente del gobierno central, tendió a aumentar, alcanzando a 3.9\% del PIB en 1998 y 5.2\% del PIB en 1999 (en este último año refleja la disminución de los ingresos resultado de la recesión). En el caso del sector público consolidado, el déficit alcanzó a $3.1 \%$ y $4.5 \%$ del PIB en los años mencionados. El mayor déficit y la constante necesidad de modificar la estructura tributaria del país son, por tanto, el reflejo de las dificultades que ha encontrado el Estado colombiano para conciliar una economía abierta con una política social más activa.

El crecimiento del tamaño del Estado estuvo acompañado de un cambio notorio en su estructura, cuyos elementos fundamentales fueron una descentralización fiscal profunda y la apertura al sector privado de sectores tradicionalmente reservados al Estado. La transferencia de rentas nacionales a los departamentos $\mathrm{y}$, especialmente, a los municipios, ha sido el componente de mayor crecimiento en las erogaciones del gobierno nacional. A su vez, los gastos de los municipios, conjuntamente con los del sistema de seguridad social, han sido los que han experimentado un mayor ritmo de aumento en el conjunto del sector público. Los procesos de privatización, de concesiones en el área de infraestructura, y de apertura en general de este último sector y del de seguridad social a la inversión privada, son los elementos más destacados en el segundo frente. Este proceso estuvo acompañado del montaje de instituciones reguladoras y supervisoras más fuertes en los sectores de infraestructura, seguridad social y financiera. En todos estos campos, sin embargo, el modelo implícito adoptado involucra en la práctica el mantenimiento de un importante grupo de empresas y entidades públicas, que en algunos campos complementan y en otros compiten con el sector privado. En el frente financiero, cabe agregar que a comienzos de la década se llevó a cabo una reforma orientada a aumentar la competencia entre distintos tipos de intermediarios, se privatizó una parte de las entidades que habían sido nacionalizadas durante la crisis financiera de comienzos de la década de los ochenta y se abrió plenamente el sector a la inversión extranjera directa. La Constitución de 1991 otorgó, por su parte, plena autonomía al Banco de la República en el manejo monetario y cambiario. 


\section{Las re formas laboral y de la seguridad social}

La reforma laboral de 1990 combinó una flexibilización parcial del mercado laboral con una mayor protección de los derechos sindicales. En sus líneas generales, esta reforma concretó muchas de las propuestas formuladas pocos años antes por la Misión de Empleo (Colombia, Contraloría General de la República, 1986). Las reformas más importantes en el primer frente fueron la flexibilización de la contratación temporal de mano de obra, la facilitación del despido después de diez años de antigüedad del trabajador, a cambio de una mayor indemnización y sujeta en cualquier caso a la demostración de "justa causa" del despido, la adopción de un sistema de salario que integra todas las remuneraciones para los trabajadores de mayores ingresos (más de 10 salarios mínimos) y la eliminación de los sobrecostos que implicaba el anterior régimen de cesantías. Esta prestación social fijaba el pago al trabajador, al momento de su retiro de la empresa, de un salario mensual por año de servicio; sin embargo, el sistema de liquidación de los retiros de la cuenta del trabajador implicaba un costo rápidamente creciente en función de su antigüedad. La reforma sustituyó este sistema por uno de ahorro forzoso en fondos de cesantía para nuevos trabajadores, y permi- tió la negociación entre la empresa y los trabajadores antiguos para trasladarlos al nuevo régimen a cambio de una indemnización. Al lado de estos cambios, orientados a flexibilizar el mercado de trabajo, fortaleció el derecho de asociación sindical y lo complementó con instrumentos legales que lo hacían efectivo.

De hecho, los resultados en términos de flexibilidad laboral no fueron evidentes, en particular por los efectos contrapuestos que tuvo la reforma posterior a la seguridad social de 1993. Los cambios en la legislación sobre contratos temporales fueron, sin duda, uno de los factores que indujeron el aumento de la participación del empleo temporal en el empleo total urbano, que subió de $15.8 \%$ a 20\% entre 1990 y 1997 (orT, 1998). No obstante, la mayor flexibilidad y la reducción de los sobrecostos asociados al anterior régimen de cesantías han sido contrarrestadas por el aumento de los costos de contratar a un trabajador nuevo y los de indemnización por despido. El primero estuvo asociado precisamente a la reforma de la seguridad social, que elevó los costos de contribución a cargo de la empresa del $13.5 \%$ al $25.5 \%$ (de los cuales hoy se destinan $13.5 \%$ para pensiones y el $12 \%$ restante a salud), ${ }^{3}$ con lo que se elevó el peso de las prestaciones sociales del $47 \%$ al $59.4 \%$ de los salarios bási$\cos$.

\section{III}

\section{Comportamiento macroeconómico}

La década de los noventa se caracterizó por fuertes ciclos de "pare y siga" de la política macroeconómica. Aunque estos ciclos respondieron en parte a choques externos, positivos o negativos, especialmente aquellos provenientes del mercado internacional de capitales, otros tuvieron origen en acontecimientos nacionales.

La década se inició en medio de crecientes presiones inflacionarias, que dieron lugar a un fuerte paquete de ajuste decretado a fines de 1990, que incluyó una contracción monetaria severa, una revaluación, un ajuste fiscal moderado (cuadro 1) y la aceleración de la puesta en marcha del programa de apertura comercial. Este paquete generó una desaceleración del crecimiento económico, un quiebre en las tendencias de la inflación y una fuerte mejoría de la balanza en cuenta corriente con el exterior.

La fuerte presión sobre las reservas internacionales y los crecientes costos cuasifiscales de las medi- das monetarias contraccionistas que se generaron a lo largo de 1991 dieron lugar a la decisión del Banco de la República de acelerar la revaluación y reducir drásticamente las tasas de interés. Al mismo tiempo, el rápido crecimiento de los ingresos tributarios dio lugar a una fuerte expansión del gasto público, aunque en el contexto de equilibrio fiscal. El resultado conjunto de estas políticas fue un auge del endeudamiento interno y externo, que generó una expansión acelerada de la demanda agregada interna en 1992-1994, la más acelerada de la historia económica de Colombia en la posguerra. La actividad económica y la inversión productiva experimentaron un auge, pero en medio de un fuerte deterioro de la balanza en cuenta corriente. La excepción más importante en términos productivos

\footnotetext{
${ }^{3}$ Véase OIт (1998) y Reina y Yanovich (1998).
} 


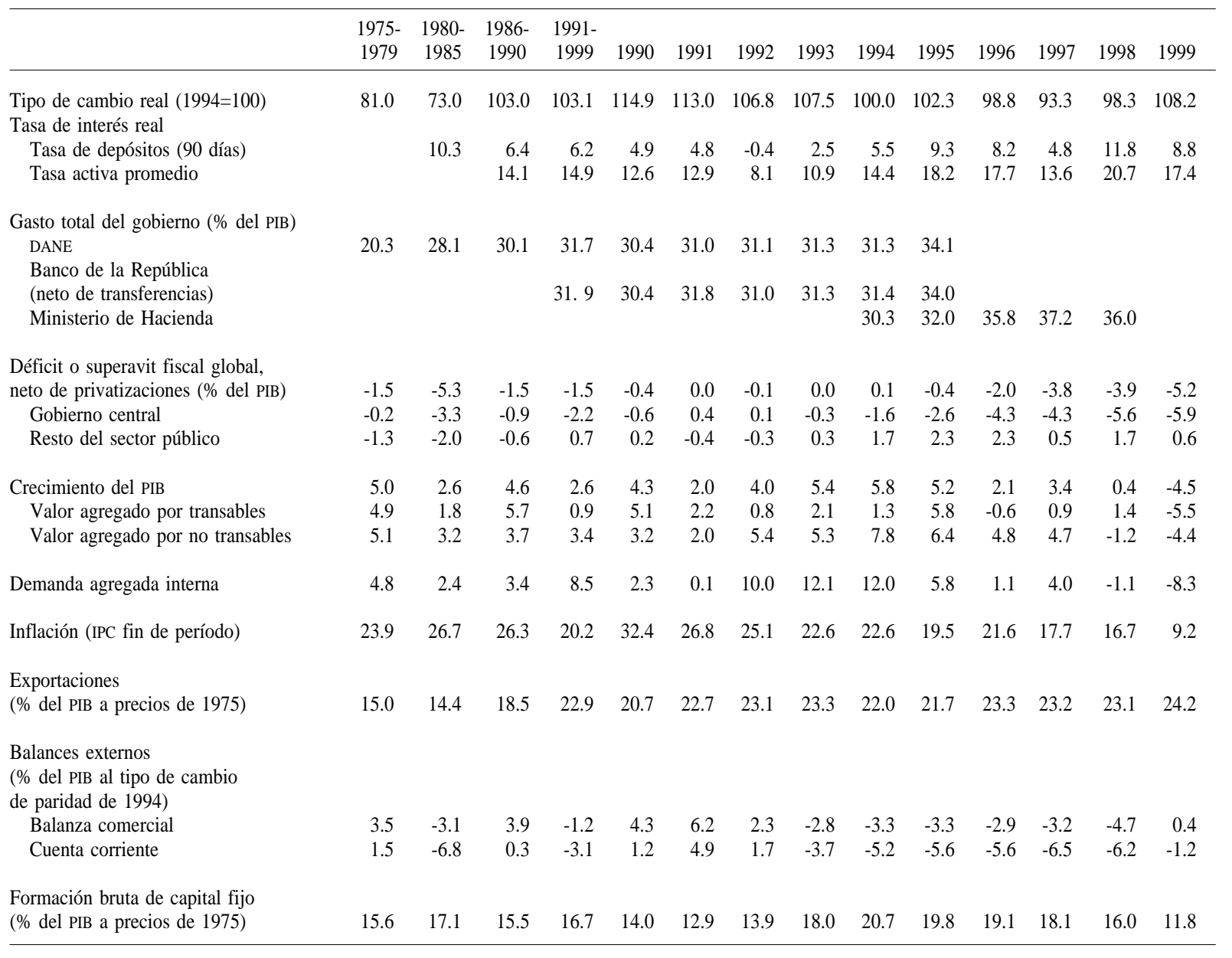

Fuentes: Banco de la República, Departamento Nacional de Estadística (DANE) y Departamento Nacional de Planeación (DNP).

fue la agricultura, que experimentó desde comienzos de la década dificultades para enfrentar la apertura externa, en un contexto caracterizado, además, por bajos precios internacionales, especialmente del café. La inflación se mantuvo bajo control - e incluso experimentó un ligero descenso adicional durante la primera fase del auge - gracias a la revaluación y al rápido crecimiento de las importaciones, pero se generaron evidentes fenómenos de inflación de activos nacionales (propiedad raíz y activos bursátiles).

La política monetaria se hizo crecientemente contraccionista a lo largo de 1994 y 1995. El fuerte control del endeudamiento externo adoptado en 1994 contribuyó también a frenar el crecimiento de la demanda privada y evitó que la política monetaria contraccionista se tradujera en una nueva revaluación real. La deman- da agregada comenzó a frenarse en 1995 y, con mayor fuerza, en 1996, generando una fuerte desaceleración de la actividad productiva y una interrupción del deterioro de la balanza en cuenta corriente con el exterior. El continuado auge del gasto público fue el factor expansionista fundamental durante estos años.

La reducción de las tasas de interés a lo largo de 1996 facilitó la reactivación de la demanda privada y de la actividad productiva en 1997. El gasto público no contribuyó a este auge y, antes bien, durante estos años se comenzaron a adoptar las primeras medidas para frenar el crecimiento del gasto del gobierno nacional, ante la evidencia de un aumento rápido del déficit fiscal. El fuerte control al endeudamiento externo frenó la tendencia a la revaluación que se hizo evidente durante 1996 (que se refleja en los promedios anuales 
de 1997), pero la cuenta corriente experimentó, en cualquier caso, un deterioro adicional moderado.

La reactivación duró poco debido a los efectos de la crisis internacional y de las medidas adoptadas para enfrentarla, en el contexto de debilidad de las cuentas externas y de la situación fiscal. La política monetaria contraccionista que se adoptó para enfrentar la crisis logró devaluar gradualmente el tipo de cambio real, mediante sucesivas modificaciones de la banda cambiaria, contraer la demanda agregada, mejorar las cuentas externas y reducir la inflación, pero a costa de inducir la peor recesión de la historia de Colombia y acelerar el deterioro de la cartera del sistema financiero. Paradójicamente, las medidas de austeridad fiscal fueron ineficaces en términos de romper la tendencia adversa del déficit fiscal y, antes bien, la reducción en los recaudos tributarios generada por la recesión, el aumento en la carga del servicio de la deuda y los gastos asociados al salvamento financiero se tradujeron en un nuevo deterioro de la situación fiscal en 1999. La alta competitividad cambiaria y el descenso en las tasas de interés durante 1999 facilitaron una moderada reactivación de la actividad productiva durante el 2000.

Visto como un todo, el crecimiento económico fue lento para los patrones históricos del país y mucho más inestable. Los promedios de crecimiento están muy afectados por la severidad de la crisis reciente, ya que hasta 1997 mostraban más bien un crecimiento moderado, sólo ligeramente inferior al de la segunda mitad de la década de los ochenta. La inestabilidad del crecimiento y, especialmente, del comportamiento de la demanda agregada fue, por el contrario, una característica sobresaliente del conjunto de la década, particularmente notoria en un país cuya tradición de gradualismo y manejo anticíclico le había generado la reputación de ser la economía con los ciclos económicos más moderados de América Latina. El elevado déficit en cuenta corriente que caracterizó el grueso de la década, asociado en parte a la tendencia a la revaluación, y el deterioro estructural de las finanzas públicas son otros hechos sobresalientes.

En términos de estructura productiva, el patrón de crecimiento económico se caracterizó por la pérdida acelerada de participación en la producción de los sectores agrícola e industrial (cuadro 2). Este hecho se hizo evidente desde los años de auge, indicando que el rápido crecimiento económico dependió durante estos años de los sectores de servicios y de la construcción, es decir de actividades no comercializables asociadas a la demanda interna. De hecho, algunas actividades agropecuarias, especialmente los cultivos de ciclo corto (cereales y oleaginosas), experimentaron una crisis severa en los primeros años de la década de los noventa. La alta dependencia de la demanda interna durante los años de auge se reflejó también en el freno a la tendencia ascendente que había experimentado el coeficiente de exportaciones desde mediados de la década de los ochenta hasta 1991 (cuadro 1).

CUADRO 2

\section{Colombia: Composición sectorial del PIB y del empleo}

(Porcentajes)

\begin{tabular}{|c|c|c|c|c|c|c|c|c|}
\hline \multirow[b]{2}{*}{ Sector económico } & \multicolumn{5}{|c|}{ PIB (precios de 1975) } & \multicolumn{3}{|c|}{ Empleo } \\
\hline & 1985 & 1991 & 1995 & 1997 & 1999 & 1991 & 1995 & 1997 \\
\hline Agricultura & 21.9 & 21.8 & 19.3 & 18.8 & 19.9 & 26.7 & 22.2 & 22.9 \\
\hline Minería & 2.3 & 4.6 & 4.3 & 4.7 & 5.7 & 1.2 & 0.8 & 0.7 \\
\hline Manufacturas & 21.2 & 21.4 & 19.0 & 18.6 & 16.9 & 15.0 & 15.7 & 13.2 \\
\hline Electricidad, gas y agua & 1.0 & 1.1 & 1.1 & 1.1 & 1.2 & 0.6 & 0.5 & 0.9 \\
\hline Construcción & 4.4 & 3.0 & 3.7 & 3.7 & 2.6 & 4.5 & 6.1 & 5.3 \\
\hline Comercio & 12.1 & 11.5 & 11.9 & 12.0 & 11.5 & 20.7 & 21.7 & 21.9 \\
\hline Transporte & 9.4 & 8.6 & 8.7 & 9.4 & 9.9 & 5.0 & 5.5 & 5.5 \\
\hline Servicios financieros & 14.2 & 14.6 & 16.3 & 17.3 & 16.5 & 3.6 & 4.6 & 5.0 \\
\hline Otros servicios & 13.2 & 13.2 & 12.9 & 14.5 & 16.1 & 22.6 & 22.8 & 24.7 \\
\hline Total & 100.0 & 100.0 & 100.0 & 100.0 & 100.0 & 100.0 & 100.0 & 100.0 \\
\hline Transables & 45.4 & 47.8 & 42.6 & 42.1 & 42.5 & 43.0 & 38.7 & 36.8 \\
\hline Urbanos & & & & & & 14.2 & 14.1 & 12.5 \\
\hline Rurales & & & & & & 28.8 & 24.7 & 24.3 \\
\hline No transables & 54.3 & 52.0 & 54.7 & 57.9 & 57.6 & 57.0 & 61.3 & 63.2 \\
\hline Urbanos & & & & & & 43.9 & 47.0 & 49.4 \\
\hline Rurales & & & & & & 13.1 & 14.3 & 13.8 \\
\hline
\end{tabular}

Fuente: DANE, Encuesta Nacional de Hogares y Cuentas Nacionales. 
La crisis de algunas actividades que habían experimentado un fuerte auge en la primera mitad de la década (la construcción y, en años recientes, los servicios financieros), unida al deterioro de la industria manufacturera, que fue particularmente marcado durante la crisis reciente, son las características de los cam- bios que experimentó la estructura productiva en la segunda mitad de la década. La minería y unos pocos servicios (transporte y servicios del gobierno hasta el inicio de los programas de ajuste fiscal) proporcionaron las únicas, aunque débiles, fuentes de crecimiento durante este período.

\section{IV}

\section{El mercado laboral}

\section{Tendencias generales}

El gráfico 1 muestra la evolución de los principales indicadores del mercado laboral en las siete ciudades principales de Colombia desde 1976 y la compara con los indicadores a nivel nacional disponibles sólo a partir de $1991 .{ }^{4}$ Allí se observa que la década de los ochenta fue un período de rápido crecimiento de la participación laboral urbana, asociada fundamentalmente a la rápida incorporación de la mujer a la fuerza laboral y ésta, a su vez, a la reducción en la fecundidad. El lento crecimiento de la economía en el primer lustro de dicha década determinó una lenta generación de empleo en las siete ciudades principales. Esta dinámica, junto con el mencionado comportamiento de la participación, determinó un notable aumento de la tasa de desempleo, que alcanzó el nivel más elevado en 1986. Desde entonces el mercado laboral experimentó un fuerte giro. A medida que la economía comenzó a recuperar su dinamismo, el empleo inició un acelerado ritmo de crecimiento, que contribuyó a reducir los niveles de desempleo.

Estas tendencias del mercado laboral urbano se mantuvieron hasta 1992. A partir de entonces, coincidiendo con la adopción de las reformas estructurales, se produjo un nuevo cambio de tendencias. Después de alcanzar un máximo en 1993, y pese al auge continuado de la demanda agregada y al rápido crecimiento económico, el ritmo de generación de empleo en las siete ciudades principales y en el conjunto del sector urbano comenzó a disminuir. Al mismo tiempo, se frenó la tendencia ascendente de la tasa de participación, lo que impidió que el menor dinamismo del empleo

\footnotetext{
${ }^{4}$ Con anterioridad a este año sólo existen dos encuestas nacionales, la de 1978 y la de 1988, pero esta última no es estrictamente comparable con las otras debido a que en el área urbana sólo cubre las siete ciudades principales.
}

GRAFICO 1

\section{Colombia: Indicadores del mercado laboral, total nacional y urbano, 1976-1999}

A. Tasas de desempleo

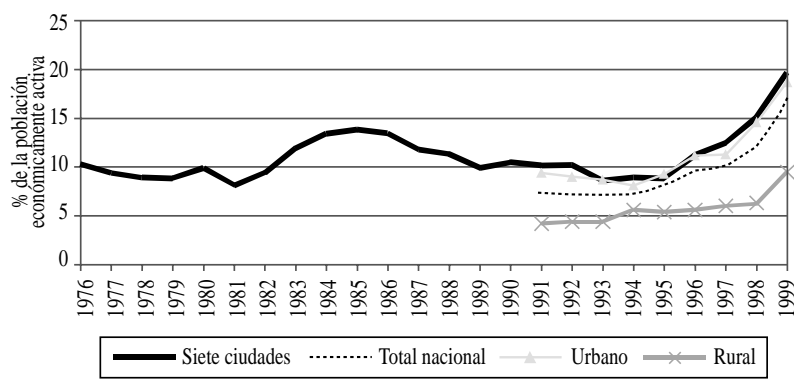

B. Tasas de ocupación

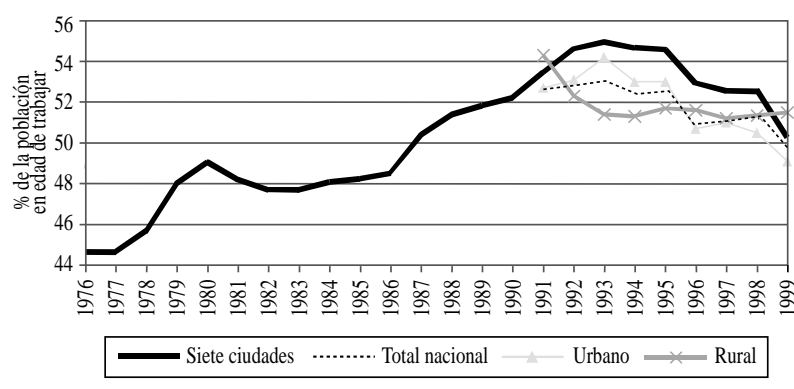

C. Tasas de participación

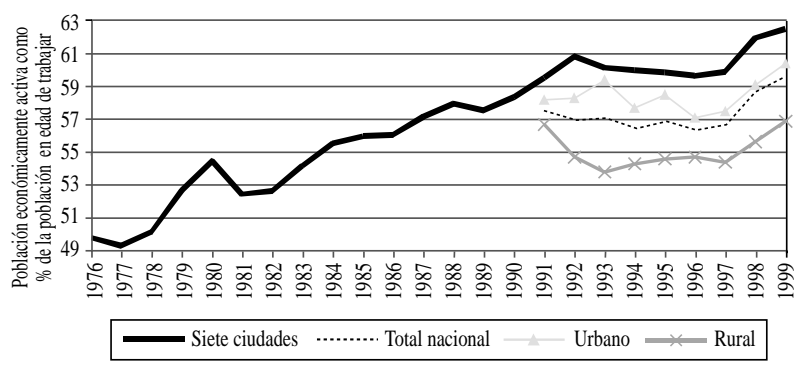


afectara la tasa de desocupación durante algunos años. En efecto, esta última alcanzó un nivel promedio de 8.7\% en las ciudades en 1993-1995, el más bajo desde comienzos de los años ochenta. Las tendencias del mercado laboral rural fueron, por el contrario, adversas durante estos años, como resultado de la fuerte crisis que experimentó el sector agropecuario. En particular, el empleo disminuyó en forma notoria en las zonas rurales entre 1991 y 1993 y la tasa de desempleo tendió a aumentar durante la primera mitad de la década de los noventa, aunque sobre niveles muy inferiores a los de las áreas urbanas. La conjunción de las tendencias opuestas de las zonas urbanas y rurales resultó en una tendencia ligeramente descendente de la tasa de ocupación - pese, nuevamente, al auge de la actividad económica - que fue compensada por una evolución similar de la participación laboral, por lo cual la tasa nacional de desempleo se mantuvo cercana al $7 \%$.

En la segunda mitad de la década se produjo un marcado deterioro del mercado laboral urbano como resultado de la fuerte caída de las tasas de ocupación y de la nueva tendencia ascendente de las tasas de participación. Esta nueva dinámica se tradujo en un aumento acelerado de la tasa de desempleo a partir de 1996, que alcanzó en 1999 los niveles más altos registrados en el país. Aunque, como veremos más adelante, la falta de dinamismo del empleo no puede atribuirse exclusivamente a la demanda interna, no cabe la menor duda que en los años más recientes esta variable ha representado un papel decisivo. En particular, las caídas más fuertes de la tasa de ocupación han coincidido con los períodos de desaceleración y recesión (1996 y 1999) y, en general, desde 1996 existe una clara asociación entre el comportamiento del empleo en las principales ciudades y la evolución del PIB trimestral (Colombia, DANE, 1999).

Como un todo, las tasas de ocupación tendieron a disminuir durante toda la década, especialmente a comienzos de ella en las zonas rurales y durante la segunda mitad en las urbanas. Para el conjunto del país, la tasa de ocupación se redujo del 53\% en los primeros años de la década a poco menos del 50\% en 1999. Ante la tendencia renovada al aumento de la participación laboral, ello se tradujo en una explosión del desempleo. Como veremos, estas tendencias estuvieron acompañadas de importantes cambios en la composición sectorial del empleo.

El cuadro 3 presenta mayores detalles de la evolución de indicadores laborales para 1991 y 1997, los dos años escogidos para analizar los efectos de las reformas. Como ya lo hemos indicado, en 1991 se concluyeron las reformas comerciales y la apertura a la IED, y se expidió la nueva carta política. En el año 1997, por su parte, los efectos de las reformas pueden apreciarse, pero también pueden aislarse los efectos de la severa crisis que afectó a la economía colombiana en años recientes.

Los indicadores que reproduce el cuadro 3 indican que las tasas de participación de las mujeres son mucho más bajas que las de los hombres. La participación laboral de las nuevas generaciones de mujeres ha aumentado, sin embargo, en las zonas urbanas, gracias a los mayores niveles de escolaridad y las menores tasas de fecundidad. Durante el período de análisis se observa una caída en la participación masculina en las áreas urbanas y rurales y una disminución en la participación de las mujeres en las áreas rurales (Henao y Parra, 1998; Farné, Vivas y Núñez, 1998; Ribero y García, 1996).

Las tasas de participación y de ocupación suben a medida que aumenta el nivel de educación, sin importar el rango de edad, el género o la zona. Entre 1991 y 1997, las tasas de ocupación disminuyeron para todos los grupos educativos, con excepción de las mujeres con mayores niveles de educación. El desempleo es más alto para las mujeres en todos los grupos educativos y para las personas con 10 a 15 años de educación. Entre 1991 y 1997 el desempleo aumentó para todas las categorías educativas, con excepción de las personas más calificadas en zonas rurales; esto último se debe, sin embargo, a su salida del mercado de trabajo, ya que la tasa de ocupación de estos trabajadores disminuyó notablemente. En el rango de escolaridad de 10 a 15 años, el aumento del desempleo de los hombres fue un poco mayor. En cuanto a la edad, la mayoría de la población se concentra en la cohorte de 25 a 50 años, en áreas urbanas y rurales, donde se alcanzan también las mayores tasas de ocupación y participación. Contrariamente, las tasas de desempleo tienden a disminuir a medida que aumenta la edad.

\section{Tendencias en la ocupación}

Para analizar en forma más detallada la dinámica del mercado laboral en el ámbito nacional se elaboró un ejercicio para descomponer los cambios en su estructura originados en los cambios en la oferta y en la demanda laborales. ${ }^{5}$ Los resultados se recogen en el

\footnotetext{
${ }^{5}$ Esta sección y las siguientes definen los principales indicadores laborales en relación con la población total y difieren, por lo tanto, de las definiciones tradicionalmente empleadas para el estudio del mercado laboral, las cuales definen dichas variables en relación con la población en edad de trabajar o económicamente activa. La metodología utilizada se desarrolla en Taylor (1998).
} 
(Porcentajes)

Por zona y género, 1991 y 1997

\begin{tabular}{lllrr}
\hline & & & 1991 & 1997 \\
\hline & \multirow{2}{*}{ Nacional } & Hombres & 78.4 & 74.0 \\
$\mathrm{~T}$ & & Mujeres & 37.9 & 38.3 \\
$\mathrm{G}$ & \multirow{2}{*}{ Urbano } & Hombres & 73.1 & 70.4 \\
$\mathrm{P}$ & & Mujeres & 40.9 & 41.5 \\
& \multirow{2}{*}{ Rural } & Hombres & 84.4 & 82.6 \\
& & Mujeres & 33.7 & 28.3 \\
\hline \multirow{3}{*}{ Nacional } & Hombres & 4.3 & 6.8 \\
$\mathrm{~T}$ & \multirow{2}{*}{ Urbano } & Mujeres & 10.7 & 13.3 \\
$\mathrm{D}$ & & Hombres & 6.4 & 8.7 \\
& \multirow{2}{*}{ Rural } & Mujeres & 12.7 & 13.3 \\
& & Hombres & 2.2 & 2.9 \\
& \multirow{2}{*}{ Nacional } & Mujeres & 7.6 & 13.4 \\
\hline \multirow{2}{*}{$\mathrm{T}$} & \multirow{2}{*}{ Urbano } & Hombres & 75.1 & 69.0 \\
0 & & Mujeres & 33.8 & 33.2 \\
& \multirow{2}{*}{ Rural } & Hombres & 68.4 & 64.2 \\
& & Mujeres & 35.7 & 36.0 \\
& & Hombres & 82.6 & 80.1 \\
\hline
\end{tabular}

Por zona y edad, 1991 y 1997

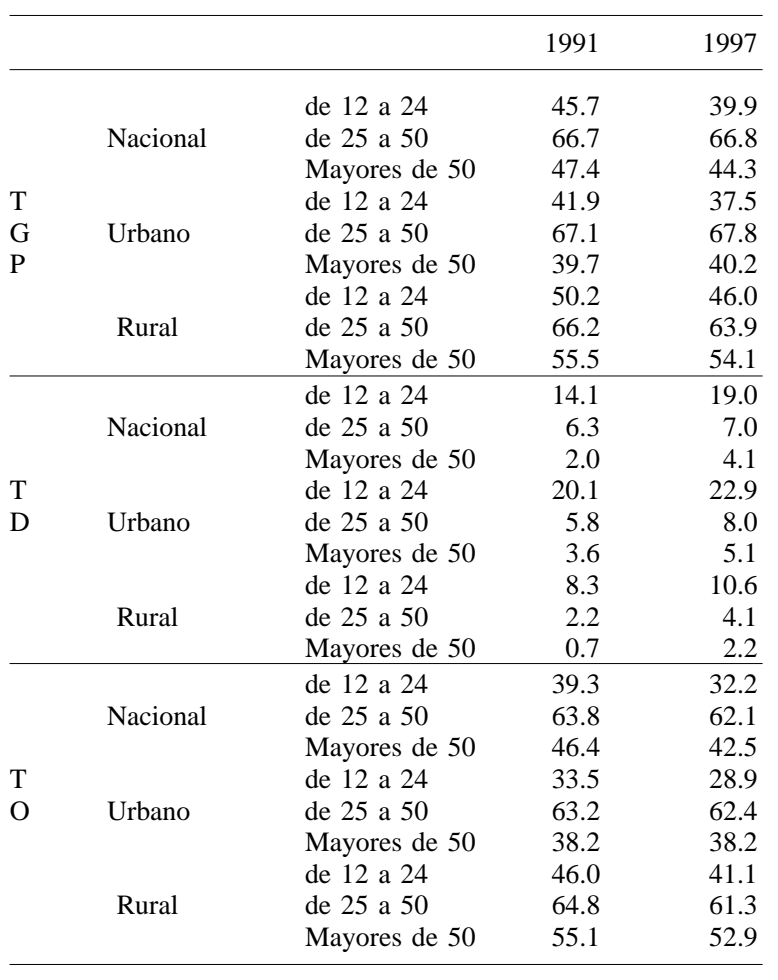

Por zona y años de escolaridad, 1991 y 1997

\begin{tabular}{|c|c|c|c|c|}
\hline & & & 1991 & 1997 \\
\hline \multirow{9}{*}{$\begin{array}{l}\mathrm{T} \\
\mathrm{G} \\
\mathrm{P}\end{array}$} & \multirow{3}{*}{ Nacional } & 9 años o menos & 54.1 & 50.2 \\
\hline & & 10 a 15 años & 64.9 & 65.7 \\
\hline & & Más de 15 años & 88.4 & 86.9 \\
\hline & \multirow{3}{*}{ Urbano } & 9 años o menos & 49.2 & 47.0 \\
\hline & & 10 a 15 años & 64.7 & 65.7 \\
\hline & & Más de 15 años & 87.9 & 86.9 \\
\hline & \multirow{3}{*}{ Rural } & 9 años o menos & 58.5 & 56.2 \\
\hline & & 10 a 15 años & 65.5 & 66.4 \\
\hline & & Más de 15 años & 96.1 & 88.4 \\
\hline \multirow{9}{*}{$\begin{array}{l}\mathrm{T} \\
\mathrm{D}\end{array}$} & \multirow{3}{*}{ Nacional } & 9 años o menos & 5.3 & 8.0 \\
\hline & & 10 a 15 años & 11.7 & 13.3 \\
\hline & & Más de 15 años & 4.0 & 5.2 \\
\hline & \multirow{4}{*}{ Urbano } & 9 años o menos & 8.4 & 10.0 \\
\hline & & 10 a 15 años & 11.5 & 13.3 \\
\hline & & Más de 15 años & 4.0 & 5.3 \\
\hline & & 9 años o menos & 3.0 & 4.8 \\
\hline & \multirow[t]{2}{*}{ Rural } & 10 a 15 años & 12.2 & 13.9 \\
\hline & & Más de 15 años & 4.3 & 2.0 \\
\hline & \multirow{3}{*}{ Nacional } & 9 años o menos & 51.2 & 46.2 \\
\hline & & 10 a 15 años & 57.3 & 57.0 \\
\hline & & Más de 15 años & 84.9 & 82.3 \\
\hline $\mathrm{T}$ & & 9 años o menos & 45.1 & 42.3 \\
\hline \multirow[t]{5}{*}{$\mathrm{O}$} & \multirow[t]{3}{*}{ Urbano } & 10 a 15 años & 57.2 & 57.0 \\
\hline & & Más de 15 años & 84.4 & 82.2 \\
\hline & & 9 años o menos & 56.7 & 53.6 \\
\hline & \multirow[t]{2}{*}{ Rural } & 10 a 15 años & 57.6 & 57.2 \\
\hline & & Más de 15 años & 92.0 & 86.6 \\
\hline
\end{tabular}

Por años de educación y género, 1991 y 1997

\begin{tabular}{|c|c|c|c|c|}
\hline & & & 1991 & 1997 \\
\hline \multirow{6}{*}{$\begin{array}{l}\mathrm{T} \\
\mathrm{G} \\
\mathrm{P}\end{array}$} & \multirow{2}{*}{9 años o menos } & Hombres & 77.6 & 71.7 \\
\hline & & Mujeres & 32.7 & 30.4 \\
\hline & \multirow{2}{*}{10 a 15 años } & Hombres & 78.4 & 77.7 \\
\hline & & Mujeres & 53.6 & 55.7 \\
\hline & \multirow{2}{*}{ Más de 15 años } & Hombres & 93.0 & 90.0 \\
\hline & & Mujeres & 81.8 & 83.0 \\
\hline \multirow{6}{*}{$\begin{array}{l}\mathrm{T} \\
\mathrm{D}\end{array}$} & \multirow{2}{*}{9 años o menos } & Hombres & 3.5 & 6.0 \\
\hline & & Mujeres & 9.2 & 12.3 \\
\hline & \multirow{2}{*}{10 a 15 años } & Hombres & 72.1 & 69.9 \\
\hline & & Mujeres & 45.0 & 46.2 \\
\hline & \multirow{2}{*}{ Más de 15 años } & Hombres & 90.1 & 86.1 \\
\hline & & Mujeres & 77.4 & 77.6 \\
\hline \multirow{6}{*}{$\begin{array}{l}\mathrm{T} \\
0\end{array}$} & \multirow{2}{*}{9 años o menos } & Hombres & 74.8 & 67.4 \\
\hline & & Mujeres & 29.7 & 26.7 \\
\hline & \multirow{2}{*}{10 a 15 años } & Hombres & 8.0 & 10.1 \\
\hline & & Mujeres & 16.0 & 17.1 \\
\hline & \multirow{2}{*}{ Más de 15 años } & Hombres & 3.2 & 4.3 \\
\hline & & Mujeres & 5.4 & 6.5 \\
\hline
\end{tabular}

$\begin{array}{lll}\text { TGP } & : & \text { Tasa global de participación } \\ \text { TD } & : & \text { Tasa de desempleo } \\ \text { TO } & : & \text { Tasa de ocupación }\end{array}$

Fuente: Cálculos propios basados en Encuestas Nacionales de Hogares. 
cuadro 4. En él se establece que los cambios originados por el lado de la oferta, tanto por factores demográficos como por cambios en la tasa global de participación, deben ser iguales a los cambios en la estructura laboral generados por factores de demanda, es decir, por los cambios en la tasa de ocupación y desempleo, ambas medidas como proporción de la población total del país.

Tres conclusiones básicas se desprenden de estos resultados. La primera, asociada a la oferta, indica que durante el período analizado, la oferta laboral aumentó en forma moderada. En 1991-1995 el efecto positivo del componente demográfico fue contrarrestado en gran medida por el descenso de la participación laboral. El efecto demográfico se frenó enteramente a mediados de la década, dando lugar, conjuntamente con el continuado descenso de la participación laboral, a una disminución en la oferta laboral en 1995-1997. Según vimos, la tendencia descendente de la participación se quebró en 1998, más allá del período de referencia para el análisis de los efectos de las reformas.

La segunda conclusión está asociada a la demanda laboral: la capacidad de generación de empleo en el conjunto del período fue muy pobre. Los resultados deficientes en materia de generación de empleo se manifestaron en una caída de la tasa de ocupación equivalente a 2.2 puntos porcentuales de la población total entre 1991 y 1997, asociada fundamentalmente a la fuerte caída relativa de la generación de empleo en los sectores productores de bienes comercializables

CUADRO 4

Colombia: Descomposición de los cambios globales en el mercado de trabajo

(Variaciones en puntos porcentuales de las tasas definidas en relación con la población total)

\begin{tabular}{lccc}
\hline & $1991-1995$ & $1995-1997$ & $1991-1997$ \\
\hline \multirow{4}{*}{ Cotal ${ }^{a}$} & \multicolumn{4}{c}{ Cambios de la oferta laboral } \\
Demográfico & 2.2 & -0.6 & 0.5 \\
Participación & -1.0 & -0.1 & 2.2 \\
& \multicolumn{4}{c}{ Absorción de la demanda laboral } \\
& \multicolumn{4}{c}{} \\
Empleo $^{a}$ & 0.7 & -2.9 & -2.2 \\
Transables & -3.9 & -3.0 & -7.0 \\
No transables & 4.7 & 0.1 & 4.8 \\
Desempleo & 0.5 & 2.1 & 2.6 \\
\hline
\end{tabular}

Fuente: Cálculos propios basados en Encuestas Nacionales de Hogares.

a La descomposición excluye el efecto conjunto de los cambios en cada uno de los componentes. internacionalmente (transables). Debe señalarse que la pérdida de empleo en los sectores transables ha sido persistente a lo largo de la década y debe asociarse, por lo tanto, por su severidad, a los efectos de las reformas estructurales. La creación de empleo en los sectores productores de bienes y servicios no comercializables internacionalmente (no transables) compensó este factor durante la fase de auge, pero dejó de operar en tal sentido durante los años posteriores de desaceleración del crecimiento económico, lo que permitió que la caída del empleo en los sectores transables se reflejara plenamente en la tasa de ocupación.

Finalmente, la favorable combinación de las tendencias de la participación y del empleo en sectores no transables tuvo efectos neutrales sobre el desempleo hasta 1995, pero experimentó un giro radical a partir de entonces, que se tradujo en un aumento de los niveles de desempleo equivalente a 2.1 puntos porcentuales de la población total entre 1995 y 1997. Según vimos, la severa recesión posterior y la renovada tendencia ascendente de la participación laboral harían que se disparara la tasa de desocupación en los años siguientes.

El análisis de las tendencias en materia de empleo puede extenderse a nivel de un dígito de la clasificación de la actividad económica, descomponiendo, además, los cambios en la tasa de empleo en cambios ponderados de la diferencia entre el crecimiento del producto per cápita y cambios de la productividad laboral de cada sector.

Los resultados de esta descomposición se presentan en el cuadro 5. De allí se desprende que el deterioro generalizado del empleo en la agricultura y la industria estuvo asociado a una fuerte disminución de la producción por habitante combinada con aumentos significativos de la productividad laboral. Como resultado de ello, entre 1991 y 1997 la tasa de empleo de los sectores transables disminuyó en un monto equivalente a 7.0 puntos porcentuales de la población total. Por el contrario, los sectores asociados a las actividades no transables, fundamentalmente servicios, experimentaron un incremento sostenido de la producción por habitante, especialmente durante el período de auge. Durante estos años, el crecimiento del producto per cápita excedió el de la productividad laboral, permitiendo generar empleo en forma dinámica en estos sectores, pero este proceso se interrumpió e incluso cambió de signo en varios sectores durante los años subsiguientes. Los efectos conjuntos de la desaceleración de la capacidad de generación de empleo en los sectores no transables desde 1996, asociada a la 
CUADRO 5

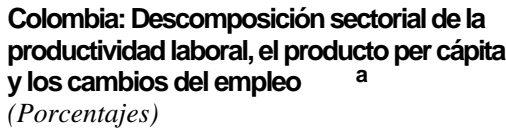

\begin{tabular}{lrr}
\hline $1991-1995$ & $1995-1997$ & $1991-1997$ \\
\hline
\end{tabular}

Crecimiento de la productividad laboral

$\begin{array}{lrrr}\text { Agricultura } & 18.7 & -4.1 & 13.8 \\ \text { Minería } & 65.6 & 22.7 & 103.2 \\ \text { Industria } & -2.8 & 18.4 & 15.2 \\ \text { Electricidad, gas y agua } & 34.1 & -38.6 & -17.6 \\ \text { Construcción } & 7.2 & 14.1 & 22.3 \\ \text { Comercio } & 13.2 & 1.1 & 14.5 \\ \text { Transporte } & 2.5 & 10.6 & 13.3 \\ \text { Servicios financieros } & -3.0 & 0.1 & -2.9 \\ \text { Otros servicios } & 11.7 & 4.4 & 16.6 \\ \text { Total } & 10.4 & 4.2 & 15.0 \\ \text { Transables } & 12.0 & 5.6 & 18.3 \\ \text { No transables } & 10.8 & 4.0 & 15.2\end{array}$

Crecimiento de la producción per cápita

$\begin{array}{lrrr}\text { Agricultura } & -0.7 & -3.9 & -4.6 \\ \text { Minería } & 9.0 & 8.5 & 18.3 \\ \text { Industria } & 2.7 & -3.7 & -1.1 \\ \text { Electricidad, gas y agua } & 11.7 & 2.5 & 14.6 \\ \text { Construcción } & 46.9 & -4.1 & 40.8 \\ \text { Comercio } & 19.8 & -0.9 & 18.7 \\ \text { Transporte } & 13.6 & 6.1 & 20.4 \\ \text { Servicios financieros } & 24.4 & 4.4 & 29.9 \\ \text { Otros servicios } & 13.4 & 9.9 & 24.6 \\ \text { Total } & 11.2 & 1.2 & 12.5 \\ \text { Transables } & 1.7 & -2.6 & -0.9 \\ \text { No transables } & 19.8 & 4.2 & 24.8\end{array}$

\begin{tabular}{lrrr} 
Agricultura & -4.4 & 0.0 & -4.3 \\
Minería & -0.4 & -0.1 & -0.5 \\
Industria & 0.8 & -2.9 & -2.1 \\
Electricidad, gas y agua & -0.1 & 0.3 & 0.2 \\
Construcción & 1.7 & -1.0 & 0.7 \\
Comercio & 1.2 & -0.4 & 0.8 \\
Transporte & 0.5 & -0.2 & 0.3 \\
Servicios financieros & 1.0 & 0.2 & 1.2 \\
Otros servicios & 0.3 & 1.2 & 1.5 \\
Total & 0.7 & -2.9 & -2.2 \\
Transables & -3.9 & -3.0 & -7.0 \\
No transables & 4.7 & 0.1 & 4.8 \\
\hline
\end{tabular}

Fuente: Cálculos propios basados en Encuestas Nacionales de Hogares.

a Los totales de las tres descomposiciones no coinciden exactamente, debido a que en las estimaciones discretas se excluye el efecto conjunto de los cambios en cada uno de los dos componentes.

desaceleración de la economía, con el deterioro de largo plazo del empleo en las actividades transables, explican, por lo tanto, la fuerte caída de la tasa de empleo total de la economía.
Estas tendencias generales a nivel sectorial tienen algunas peculiaridades. De una parte, sobresale el marcado deterioro del empleo en el sector agrícola entre 1991 y 1995. Ello es particularmente notorio en las zonas rurales, donde la participación del empleo agrícola cayó en más de cuatro puntos porcentuales durante estos años (cuadro 2). Por el contrario, entre 1995 y 1997, la caída del empleo de los sectores transables tuvo su origen fundamentalmente en el sector industrial, aunque en esta ocasión, el fenómeno estuvo ligado al deterioro del empleo en las zonas urbanas, reflejo tanto de los efectos del ajuste estructural como de la desaceleración de la actividad económica.

Como un todo, estas tendencias se tradujeron en un aumento acelerado de la participación de los sectores no transables en el empleo total, que se elevó de $57.0 \%$ en 1991 a $63.2 \%$ en 1997 (cuadro 2). El comportamiento procíclico del empleo fue particularmente notorio en el sector de la construcción. En efecto, este sector experimentó un fuerte auge en 1991-1995, que fue sucedido por una recesión, y sus efectos se advierten claramente sobre la generación de empleo: la participación del sector de la construcción en el empleo total subió de $4.5 \%$ en 1991 a $6.1 \%$ en 1995 y luego descendió a 5.3\% en 1997.

El análisis precedente se puede extender para estudiar la dinámica de la generación de empleo en cada sector de acuerdo con el nivel educativo de los trabajadores, por posición ocupacional y por género. $\mathrm{Al}$ relacionar la dinámica de las tasas de empleo por sectores productivos y por nivel de escolaridad se encuentran dos patrones bien definidos (cuadro 6). Por una parte, a lo largo de la década hubo una caída en la tasa de empleo de los trabajadores con menor instrucción, que fue mucho más acentuada en los sectores transables. Por otra, la generación de empleo calificado se concentró en los sectores no transables, especialmente en los servicios financieros y otros servicios, mientras se estancó la generación de empleo con mayores requisitos educativos en los sectores transables.

Con respecto al primer punto, es importante señalar que entre 1991 y 1995 la caída de la tasa de empleo para los trabajadores menos calificados, entendidos como aquellos con alguna educación primaria (05 años) o secundaria incompleta (6-10 años), estuvo dominada por el sector agrícola. Por el contrario, entre 1995 y 1997 la caída en la tasa de empleo para estos trabajadores fue notoria en el sector industrial. En el caso de los sectores no transables, se observa un claro 
(Porcentajes)

\begin{tabular}{|c|c|c|c|c|c|c|c|c|c|}
\hline \multirow{2}{*}{$\begin{array}{l}\text { Años promedio de } \\
\text { educación/Ramas de actividad }\end{array}$} & \multicolumn{3}{|c|}{$0-5$ años } & \multicolumn{3}{|c|}{ 6-10 años } & \multicolumn{3}{|c|}{11 años } \\
\hline & 1991-1995 & 1995-1997 & 1991-1997 & 1991-1995 & 1995-1997 & $1991-1997$ & $1991-1995$ & 1995-1997 & $1991-1997$ \\
\hline Agricultura & -3.3 & -0.2 & -3.5 & -0.6 & -0.1 & -0.7 & -0.2 & 0.2 & 0.0 \\
\hline Minería & -0.2 & -0.2 & -0.4 & 0.0 & -0.1 & -0.1 & 0.0 & 0.1 & 0.0 \\
\hline Industria & -0.1 & -1.1 & -1.2 & 0.1 & -1.3 & -1.2 & 0.9 & -0.6 & 0.3 \\
\hline Electricidad, gas y agua & 0.0 & 0.1 & 0.0 & 0.0 & 0.0 & 0.0 & 0.0 & 0.1 & 0.1 \\
\hline Construcción & 0.8 & -0.5 & 0.3 & 0.6 & -0.6 & 0.0 & 0.2 & 0.0 & 0.2 \\
\hline Comercio & 0.0 & -0.4 & -0.4 & 0.0 & -0.4 & -0.4 & 1.0 & 0.1 & 1.1 \\
\hline Transporte & 0.1 & -0.4 & -0.3 & 0.2 & -0.2 & 0.0 & 0.3 & 0.2 & 0.5 \\
\hline Servicios Financieros & 0.1 & 0.0 & 0.2 & 0.2 & -0.1 & 0.0 & 0.3 & 0.0 & 0.3 \\
\hline Otros servicios & -0.3 & 0.1 & -0.3 & -0.2 & -0.2 & -0.4 & 0.7 & 0.3 & 1.1 \\
\hline Total & -3.0 & -2.5 & -5.6 & 0.3 & -3.0 & -2.7 & 3.2 & 0.3 & 3.5 \\
\hline Transables & -3.7 & -1.4 & -5.1 & -0.5 & -1.4 & -2.0 & 0.6 & -0.3 & 0.3 \\
\hline No transables & 0.6 & -1.1 & -0.5 & 0.8 & -1.6 & -0.7 & 2.6 & 0.6 & 3.2 \\
\hline \multirow{2}{*}{$\begin{array}{l}\text { Años promedio de } \\
\text { educación/Ramas de actividad }\end{array}$} & \multicolumn{3}{|c|}{ 12-15 años } & \multicolumn{3}{|c|}{16 y más años } & \multicolumn{3}{|c|}{ Total } \\
\hline & 1991-1995 & 1995-1997 & 1991-1997 & 1991-1995 & 1995-1997 & 1991-1997 & 1991-1995 & 1995-1997 & 1991-1997 \\
\hline Agricultura & -0.1 & 0.0 & 0.0 & -0.1 & 0.1 & 0.0 & -4.4 & 0.0 & -4.3 \\
\hline Minería & 0.0 & 0.0 & 0.0 & -0.1 & 0.1 & 0.0 & -0.4 & -0.1 & -0.5 \\
\hline Industria & 0.0 & -0.1 & -0.1 & 0.0 & 0.1 & 0.1 & 0.8 & -2.9 & -2.1 \\
\hline Electricidad, gas y agua & 0.0 & 0.0 & 0.0 & 0.0 & 0.1 & 0.1 & -0.1 & 0.3 & 0.2 \\
\hline Construcción & 0.0 & 0.0 & 0.1 & 0.1 & 0.1 & 0.1 & 1.7 & -1.0 & 0.7 \\
\hline Comercio & 0.1 & 0.0 & 0.2 & 0.0 & 0.3 & 0.3 & 1.2 & -0.4 & 0.8 \\
\hline Transporte & 0.0 & 0.1 & 0.0 & 0.0 & 0.1 & 0.1 & 0.5 & -0.2 & 0.3 \\
\hline Servicios Financieros & 0.2 & 0.0 & 0.2 & 0.2 & 0.3 & 0.5 & 1.0 & 0.2 & 1.2 \\
\hline Otros servicios & -0.2 & 0.5 & 0.3 & 0.3 & 0.6 & 0.8 & 0.3 & 1.2 & 1.5 \\
\hline Total & 0.0 & 0.6 & 0.7 & 0.2 & 1.7 & 2.0 & 0.7 & -2.9 & -2.2 \\
\hline Transables & -0.1 & -0.1 & -0.2 & -0.3 & 0.3 & 0.0 & -3.9 & -3.0 & -7.0 \\
\hline No transables & 0.1 & 0.7 & 0.8 & 0.5 & 1.5 & 2.0 & 4.7 & 0.1 & 4.8 \\
\hline
\end{tabular}

Fuente: Cálculos propios basados en Encuestas Nacionales de Hogares.

a Contribución de cada sector al crecimiento del empleo relativo a la población total. Los totales de las tres descomposiciones no coinciden exactamente, debido a que en las estimaciones discretas se excluye el efecto conjunto de los cambios en cada uno de los dos componentes.

comportamiento cíclico de la generación de empleo de baja calificación, estrechamente asociado a la dinámica de la construcción. En efecto, durante la fase de expansión este sector fue el más dinámico generador de empleo de trabajadores con bajo nivel educativo; por el contrario, durante la fase de ajuste este sector fue, después de la industria, el que más contribuyó al deterioro de la tasa de ocupación de estos trabajadores. Esta dinámica sugiere, por lo tanto, que en los sectores no transables la generación de empleo de baja instrucción ha estado asociada al ciclo económico propio de cada sector. Por el contrario, en los sectores productores de bienes comercializables ha habido un deterioro permanente de la capacidad de generación de empleo de trabajadores con bajo nivel educativo.

La dinámica sectorial de la tasa de empleo de los trabajadores con alta calificación, aquellos con educación universitaria politécnica o incompleta (12-15 años) y completa (16 años y más), ha sido restringida, con la excepción de los servicios financieros y otros servicios. La generación de empleo calificado en los sectores de servicios financieros y otros servicios explica, por sí sola, dos terceras partes del aumento de la tasa de empleo de los de mayor nivel educativo en toda la economía entre 1991 y 1997. En el caso intermedio, de personas con educación secundaria completa (11 años), el sector comercio ha sido, conjuntamente con otros servicios, la fuente principal de generación de empleo, con una contribución también importante del sector transporte.

El comportamiento del crecimiento de la tasa de empleo por posición ocupacional y por género muestra, por su parte, tres rasgos relevantes (cuadro 7). El primero es el marcado ciclo que tiene la generación de empleo asalariado en el sector privado. En efecto, durante la fase de expansión de la economía esta posición ocupacional fue la más dinámica en términos de 
Colombia: Dinámica del empleo por posición ocupacional y género

(Porcentajes)

\begin{tabular}{|c|c|c|c|c|c|c|c|c|c|}
\hline & \multicolumn{3}{|c|}{ 1991-1995 } & \multicolumn{3}{|c|}{$1995-1997$} & \multicolumn{3}{|c|}{ 1991-1997 } \\
\hline & Hombre & Mujer & Total & Hombre & Mujer & Total & Hombre & Mujer & Total \\
\hline Trabajador familiar sin remuneración & -1.7 & -1.1 & -2.8 & 0.0 & -0.3 & -0.2 & -1.7 & -1.3 & -3.0 \\
\hline Empleados particulares & 1.5 & 2.2 & 3.7 & -2.4 & -1.0 & -3.4 & -0.9 & 1.2 & 0.3 \\
\hline Empleados gobierno & -1.1 & -0.8 & -1.9 & -0.8 & 0.5 & -0.3 & -1.9 & -0.3 & -2.2 \\
\hline Empleados domésticos & 0.0 & -0.2 & -0.2 & 0.1 & -0.3 & -0.2 & 0.1 & -0.5 & -0.4 \\
\hline Trabajador por cuenta propia & 1.1 & 1.1 & 2.2 & 1.8 & 0.0 & 1.8 & 2.9 & 1.1 & 4.0 \\
\hline Patrón o empleador & -0.5 & 0.2 & -0.3 & -0.5 & 0.0 & -0.5 & -1.0 & 0.1 & -0.9 \\
\hline Total & -0.8 & 1.5 & 0.7 & -1.8 & -1.1 & -2.9 & -2.6 & 0.4 & -2.2 \\
\hline
\end{tabular}

Fuente: Cálculos propios basados en Encuestas Nacionales de Hogares.

a Contribución de cada sector al crecimiento del empleo relativo a la población total.

Los totales de las tres descomposiciones no coinciden exactamente, debido a que en las estimaciones discretas se excluye el efecto conjunto de los cambios en cada uno de los dos componentes.

generación de empleo. En cambio, entre 1995 y 1997 este mismo rubro concentró el grueso de la contracción de la demanda laboral. El segundo es la importante dinámica que muestra el empleo de los trabajadores por cuenta propia a lo largo de la década. La conjunción de estos dos factores durante los años de desaceleración del crecimiento es, sin duda, un indicio de que hubo un proceso de informalización del empleo. Finalmente, las tasas de empleo femenino mostraron un aumento relativo; no obstante, en los años más recientes esta tendencia experimentó una importante desaceleración.

Los resultados globales sugieren que el escaso dinamismo del empleo está estrechamente asociado a las actividades transables. Por su parte, las actividades no transables sólo fueron capaces de absorber la masa de población que buscaba empleo por primera vez o que fue desplazada de los sectores transables durante los años de auge. Los resultados sugieren también que el cambio en la dinámica del empleo por niveles de calificación está estrechamente asociado a los cambios en la estructura sectorial de la producción: el deterioro de los sectores transables (especialmente en la agricultura y la industria) ha incidido en una caída permanente de la demanda de mano de obra de bajo nivel educativo, al tiempo que el auge de algunos sectores no transables (servicios financieros y otros servicios) ha generado fundamentalmente demanda de mano de obra calificada.

\section{Cambios en la dinámica de la productividad}

Para analizar el peso que han tenido en el aumento de la productividad laboral del conjunto de la economía el comportamiento de dicha variable en sectores pro- ductivos específicos, por una parte, y los cambios en la composición productiva o del empleo, por otra, el cuadro 8 muestra los resultados de tres ejercicios distintos de descomposición de las variaciones de la productividad laboral total. El primero (A) descompone dichas variaciones en la suma sectorial de la diferencia entre los cambios del crecimiento del producto y del empleo, ponderado cada uno por su participación en el producto y el empleo totales. El segundo y tercero (B y C) descomponen el crecimiento de la productividad laboral total en un promedio ponderado de los cambios en la productividad de cada sector más un término de reasignación del producto o del empleo entre sectores, respectivamente.

Los resultados de la primera descomposición sugieren que el aumento de productividad de la economía se produjo por la combinación de varios factores. La contribución de los sectores transables al crecimiento de la productividad total de la economía fue importante, pero estuvo asociada, en la agricultura y la industria, a una combinación de bajos niveles de crecimiento del producto y una acelerada caída del empleo en estos sectores. Esto es particularmente cierto en el sector agrícola en el período 1991-1995, y en la industria en 1995-1997, es decir, durante los años de ajuste más severo de estos sectores. Por el contrario, en el caso de la minería, la fuerte contribución al crecimiento global de la productividad de la economía se dio en un contexto de fuerte y persistente aumento de la producción. Algo similar aconteció en los sectores no transables durante el período de auge, que se mantuvo, aunque a un menor ritmo, hasta 1997.

La segunda y tercera descomposiciones constituyen ejercicios alternativos, aunque equivalentes. Su 
CUADRO 8

Colombia: Descomposición del crecimiento medio anual de la productividad laboral

(En porcentajes)

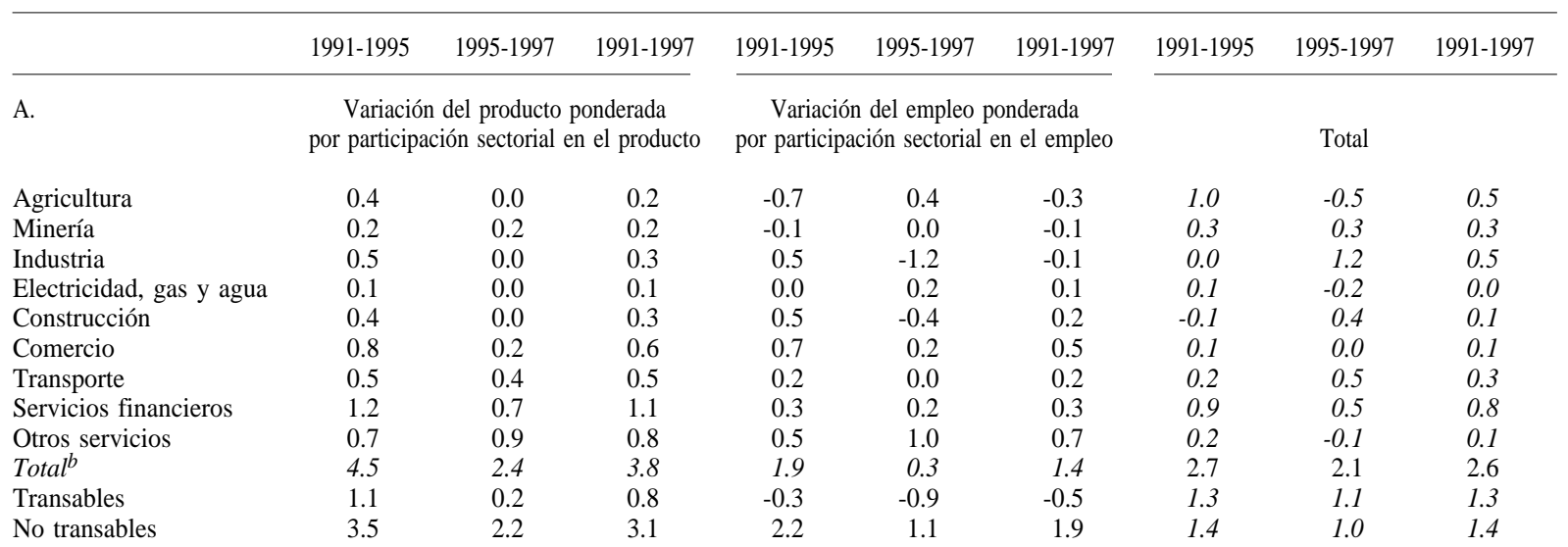

B.

Agricultura
Minería
Industria
Electricidad, gas y agua
Construcción
Comercio
Transporte
Servicios financieros
Servicios
Total
Transables
No transables

C.

Agricultura
Minería
Industria
Electricidad, gas y agua
Construcción
Comercio
Transporte
Servicios financieros
Servicios
Total
Transables
No transables

Agricultura

Electricidad, gas y agua

No transables
Productividad ponderada por el producto

$\begin{array}{rrr}1.0 & -0.4 & 0.5 \\ 0.7 & 0.4 & 0.8 \\ -0.1 & 1.8 & 0.5 \\ 0.1 & -0.2 & 0.0 \\ 0.1 & 0.3 & 0.1 \\ 0.4 & 0.1 & 0.3 \\ 0.1 & 0.5 & 0.2 \\ -0.1 & 0.0 & -0.1 \\ 0.4 & 0.3 & 0.4 \\ 2.5 & 2.1 & 2.5 \\ 1.4 & 1.2 & 1.4 \\ 1.4 & 1.1 & 1.3\end{array}$

Productividad ponderada por el empleo

$\begin{array}{rr}1.2 & -0.5 \\ 0.2 & 0.1 \\ -0.1 & 1.4 \\ 0.1 & -0.1 \\ 0.1 & 0.4 \\ 0.7 & 0.1 \\ 0.0 & 0.3 \\ 0.0 & 0.0 \\ 0.7 & 0.5 \\ 2.7 & 2.3 \\ 1.3 & 1.1 \\ 1.5 & 1.2\end{array}$

Término de reasignación

$\begin{array}{rrrrrr}-0.1 & 0.0 & 0.0 & 0.9 & -0.4 & 0.5 \\ 0.1 & 0.2 & 0.2 & 0.9 & 0.7 & 0.9 \\ 0.2 & 0.0 & 0.1 & 0.0 & 1.8 & 0.6 \\ 0.0 & 0.0 & 0.0 & 0.1 & -0.2 & 0.0 \\ -0.2 & 0.0 & -0.1 & -0.2 & 0.3 & 0.0 \\ -0.7 & -0.1 & -0.5 & -0.3 & -0.1 & -0.2 \\ 0.2 & 0.2 & 0.2 & 0.3 & 0.6 & 0.4 \\ 0.9 & 0.5 & 0.8 & 0.8 & 0.5 & 0.8 \\ -0.5 & -0.7 & -0.6 & -0.1 & -0.4 & -0.3 \\ 0.0 & 0.0 & 0.0 & 2.7 & 2.1 & 2.6 \\ 0.1 & 0.0 & 0.1 & 1.5 & 1.3 & 1.5 \\ -0.4 & -0.2 & -0.3 & 1.0 & 0.9 & 1.0\end{array}$

Término de reasignación

Productividad laboral tota

$\begin{array}{rrrrrr}0.1 & 0.0 & 0.1 & 1.3 & -0.5 & 0.7 \\ -0.2 & -0.2 & -0.2 & 0.0 & 0.0 & 0.0 \\ 0.2 & -0.3 & 0.0 & 0.1 & 1.1 & 0.3 \\ 0.0 & 0.2 & 0.0 & 0.0 & 0.1 & 0.0 \\ -0.2 & 0.1 & -0.1 & -0.1 & 0.6 & 0.1 \\ -0.3 & -0.1 & -0.2 & 0.4 & 0.0 & 0.3 \\ 0.2 & 0.0 & 0.1 & 0.2 & 0.3 & 0.2 \\ 1.1 & 0.5 & 0.9 & 1.0 & 0.5 & 0.9 \\ -0.2 & -0.4 & -0.3 & 0.4 & 0.1 & 0.3 \\ 0.6 & -0.2 & 0.3 & 2.7 & 2.1 & 2.6 \\ 0.0 & -0.1 & -0.1 & 1.3 & 1.1 & 1.3 \\ -0.2 & -0.1 & -0.2 & 1.4 & 1.0 & 1.4\end{array}$

Fuente: Cálculos propios basados en Encuestas Nacionales de Hogares.

a Contribución de cada sector al crecimiento del empleo relativo a la población total.

b Los totales de las tres descomposiciones no coinciden exactamente, debido a que en las estimaciones discretas se excluye el efecto conjunto de los cambios en cada uno de los dos componentes.

aspecto más sobresaliente lo constituye el hecho de que la productividad asociada a la dinámica de cada uno de los sectores fue el factor determinante del crecimiento de la productividad total de la economía, mientras el efecto de la reasignación del producto o de la mano obra entre sectores fue muy pequeño. El crecimiento relativo y la reasignación de fuerza de trabajo hacia el sector financiero fue una fuente de aumento de productividad, pero estuvo compensada por procesos similares de crecimiento relativo de otros sectores no transables, especialmente comercio y otros servicios. 


\section{La dinámica de los ingresos salariales}

A lo largo de los años ochenta los ingresos laborales mantuvieron una moderada tendencia a la baja (gráfi$\cos 2$ y 3). Por el contrario, los ingresos laborales reales aumentaron en forma sistemática a partir de 1991, tanto por ramas de actividad económica como por nivel educativo. Por ramas de actividad económica hubo un aumento generalizado de los salarios en todos los sectores, particularmente en el gobierno y en servicios financieros. En el sector de la construcción el aumento de los ingresos fue también notorio a principios de la década, pero se interrumpió bruscamente con el fin del auge.
La dinámica de los ingresos laborales vista por niveles educativos ofrece otra perspectiva (gráfico 3 ). Si bien al comenzar los noventa los ingresos laborales se incrementaron en todos los niveles educativos, esta tendencia no se mantuvo. De hecho, desde 1994 se comenzó a percibir un estancamiento de los ingresos laborales en todos los niveles educativos con excepción de los universitarios, y desde 1996 se ha empezado a producir una caída escalonada de los ingresos salariales, excepto de los trabajadores con educación universitaria o politécnica, incompleta y completa. La dinámica salarial experimentada desde 1996 es un indicio de que los ingresos de los trabajadores con menor nivel educativo están más asociados al ciclo económico que el de

GRAFICO 2

Colombia: Salarios reales por ramas de actividad económica (Indice diciembre de 1994=100)
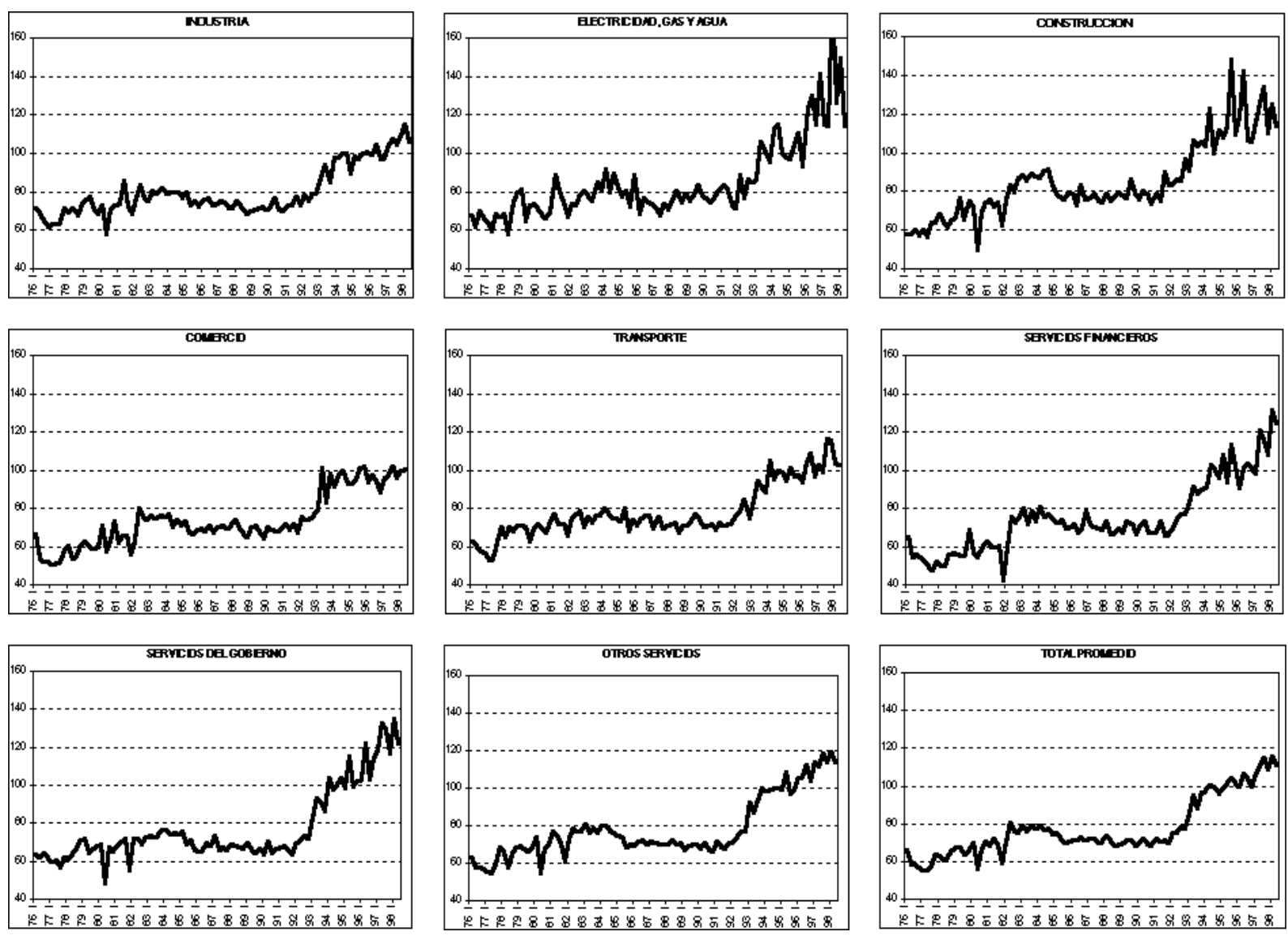

Fuente: Encuesta Nacional de Hogares. 
A. Ingresos laborales urbanos reales (Indice diciembre de 1994=100)
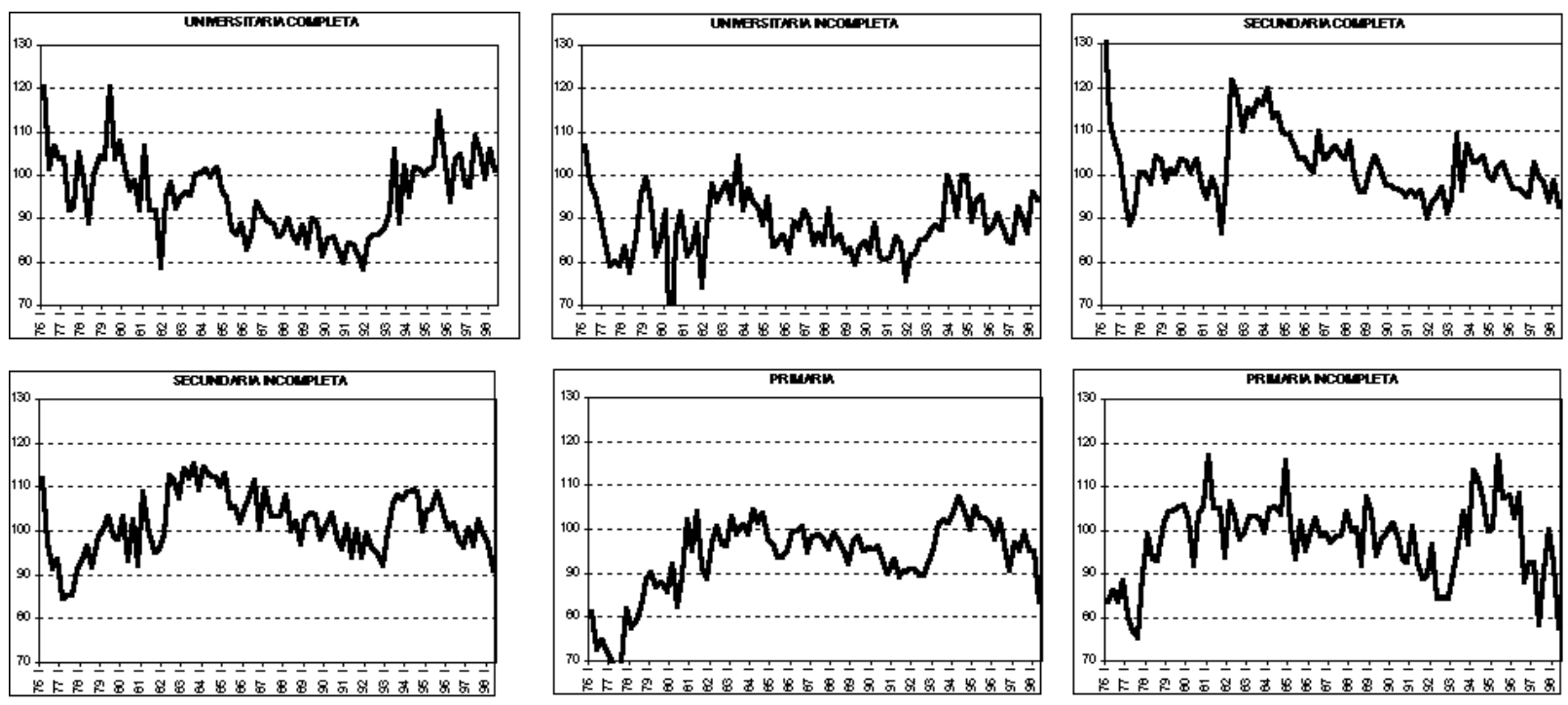

B. Ingresos laborales urbanos relativos (Indice diciembre de 1994=100)
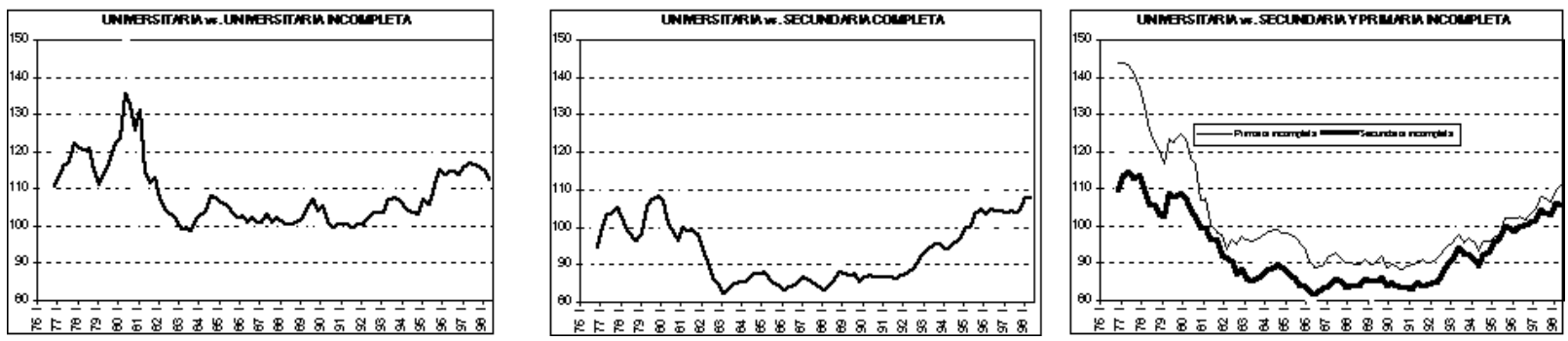

Fuente: Encuesta Nacional de Hogares.

los grupos de trabajadores con más instrucción. De otra parte, el aumento sostenido de los salarios de los de mayor nivel educativo, especialmente de trabajadores con estudios universitarios completos, en relación con todos los otros niveles educativos indica que, tanto debido a la recomposición sectorial hacia sectores transables como a los cambios tecnológicos inducidos por el proceso de reformas, la demanda relativa de mano de obra calificada ha aumentado, y quizás que la oferta de trabajadores con alto nivel educativo no ha respondido al mismo ritmo a estos cambios en la composición de la demanda laboral (cuadro 9).
La dinámica salarial contrasta con el comportamiento del salario mínimo, que después de descender $6 \%$ a comienzos de la década (entre 1985-1989 y 19911992) se mantuvo relativamente estable. Como resultado de este comportamiento y del aumento de los salarios medios, la proporción de la población por debajo del salario mínimo ha descendido. En efecto, la OIT (1998) ha estimado que el porcentaje de trabajadores asalariados con ingresos inferiores a dos salarios mínimos legales pasó de representar cerca de $80 \%$ de la mano de obra en 1990 a tan sólo $63 \%$ en 1997. 


\begin{tabular}{|c|c|c|c|c|c|c|c|c|c|c|c|c|c|c|}
\hline & \multicolumn{2}{|c|}{ Quintil 1} & \multicolumn{2}{|c|}{ Quintil 2} & \multicolumn{2}{|c|}{ Quintil 3} & \multicolumn{2}{|c|}{ Quintil 4} & \multicolumn{2}{|c|}{ Quintil 5} & \multicolumn{2}{|c|}{ Total } & \multicolumn{2}{|c|}{ Gini recalculado } \\
\hline & 1993 & 1997 & 1993 & 1997 & 1993 & 1997 & 1993 & 1997 & 1993 & 1997 & 1993 & 1997 & 1993 & 1997 \\
\hline Educación & 22.9 & 28.0 & 8.1 & 11.0 & 5.2 & 5.5 & 2.8 & 2.7 & 0.9 & 0.9 & 3.4 & 3.6 & 0.513 & 0.541 \\
\hline Primaria & 16.8 & 19.9 & 4.4 & 6.6 & 2.1 & 2.4 & 0.7 & 0.7 & 0.1 & 0.1 & 1.6 & 1.7 & 0.520 & 0.548 \\
\hline Secundaria & 5.6 & 7.0 & 3.1 & 3.5 & 2.1 & 1.8 & 1.1 & 0.7 & 0.2 & 0.1 & 1.2 & 1.0 & 0.528 & 0.558 \\
\hline Universitaria & 0.6 & 1.2 & 0.6 & 1.0 & 1.1 & 1.2 & 1.0 & 1.4 & 0.5 & 0.7 & 0.7 & 1.0 & 0.535 & 0.564 \\
\hline Salud & 11.9 & 45.5 & 6.5 & 15.3 & 5.3 & 9.5 & 3.0 & 2.3 & 0.9 & -0.4 & 2.9 & 4.2 & 0.520 & 0.523 \\
\hline Régimen subsidiado & 10.7 & 42.8 & 4.2 & 12.8 & 2.7 & 6.3 & 1.0 & 1.2 & 0.3 & 0.1 & 1.5 & 3.5 & 0.524 & 0.530 \\
\hline Régimen contributivo & 1.3 & 2.7 & 2.3 & 2.5 & 2.6 & 3.2 & 1.9 & 1.2 & 0.6 & -0.6 & 1.4 & 0.7 & 0.532 & 0.558 \\
\hline Servicios públicos & 5.8 & 13.3 & 4.3 & 5.4 & 3.6 & 3.6 & 2.4 & 1.9 & 1.1 & 0.6 & 2.2 & 2.1 & 0.528 & 0.553 \\
\hline Agua & 1.6 & 4.6 & 1.2 & 1.8 & 1.0 & 1.3 & 0.6 & 0.7 & 0.3 & 0.2 & 0.6 & 0.8 & 0.533 & 0.561 \\
\hline Luz & 4.2 & 8.7 & 3.1 & 3.5 & 2.6 & 2.3 & 1.8 & 1.2 & 0.9 & 0.4 & 1.6 & 1.3 & 0.530 & 0.557 \\
\hline Total & 40.7 & 86.8 & 18.9 & 31.7 & 14.1 & 18.6 & 8.2 & 6.9 & 2.9 & 1.1 & 8.5 & 9.9 & 0.492 & 0.491 \\
\hline Dato de referencia & & & & & & & & & & $i$ ante & del sub & dio: & 0.535 & 0.565 \\
\hline
\end{tabular}

Fuente: Sánchez y Núñez (1999).

\section{$\mathrm{V}$ \\ Efectos del mercado laboral en la distribución del ingreso}

\section{Una breve revisión de la literatura}

Diversos estudios recientes muestran que durante gran parte de la década de los ochenta se mantuvo la tendencia a la mejoría de la distribución del ingreso en las zonas urbanas que se había iniciado en los años setenta, pero que esa tendencia se invirtió a fines de la década de los ochenta y fue sucedida por un deterioro distributivo relativamente fuerte en los años noventa. ${ }^{6}$ En las zonas rurales se observan tendencias opuestas: deterioro distributivo entre 1978 y 1988 sucedido por un mejoramiento en la primera mitad de los años noventa, que sólo se invirtió parcialmente en la segunda. Aunque estas tendencias opuestas tendieron a compensarse en los primeros años de la década de los noventa, la evolución adversa característica de las zonas urbanas terminó prevaleciendo, lo que generó un deterioro

\footnotetext{
${ }^{6}$ Cabe señalar que una característica común de los estudios recientes es la corrección de las encuestas de hogares por problemas de censuramiento de los ingresos más altos. Los métodos de corrección se suman a los problemas típicos de procesamiento de las encuestas de hogares (correcciones por ingresos no declarados o subdeclarados, consistencia con cuentas nacionales, etc.) para generar discrepancias entre las estimaciones de diferentes autores.
}

distributivo en el conjunto del país (Colombia, DNP/ PNUD, 1998; Leibovich y Núñez, 1999; Ocampo, Pérez, Tovar y Lasso, 1998; Sánchez y Núñez, 1999; Vélez, Kugler y Bouillon, 1999). El cuadro 10 muestra, en efecto, que la distribución primaria del ingreso a nivel nacional se deterioró entre 1991 y 1997 en poco menos de dos puntos porcentuales del coeficiente de Gini, como producto de un movimiento adverso de más de cuatro puntos en las zonas urbanas, que superó el efecto de alza de cerca de cuatro puntos en las zonas rurales. Sin embargo, esa evolución en la distribución primaria del ingreso a nivel nacional estuvo compensada por el efecto distributivo favorable de la expansión del gasto público social y de su mejor focalización hacia los sectores más pobres (Sánchez y Núñez, 1999), es decir, por un mejoramiento en la distribución secundaria del ingreso. Esto indicaría que la distribución global (primaria y secundaria) no experimentó ninguna tendencia clara a lo largo de la década.

En términos rural-urbanos, Ocampo, Pérez, Tovar y Lasso (1998) y Sánchez y Núñez (1999) muestran que en la década de los noventa hubo una redistribución masiva de ingresos entre la ciudad y el campo, con lo cual los grandes ganadores fueron los sectores de más altos ingresos de las zonas urbanas y los ma- 
yores perdedores los sectores de mayores ingresos de las zonas rurales. ${ }^{7}$ El primer estudio refleja, ante todo, el incremento de los ingresos laborales relativos de los trabajadores más calificados, en tanto que el segundo muestra una especie de "nivelación hacia abajo" de los ingresos rurales generada por la crisis de la agricultura comercial. Por su parte, en términos de género, Vélez, Kugler y Bouillon (1999) muestran que la brecha de ingresos de los hombres disminuyó entre 1978 y 1988, pero se incrementó notoriamente entre 1988 y 1995. En contraste, la tendencia hacia una mayor concentración del ingreso entre las mujeres fue una característica del conjunto del período 1978-1995.

De acuerdo con Ocampo, Pérez, Tovar y Lasso (1998), las tendencias distributivas favorables características de las zonas urbanas en los ochenta pueden explicarse como el resultado de la conjunción del aumento y mejor distribución de la educación, de la reducción de la brecha de ingresos por nivel educativo, de las buenas oportunidades laborales que existieron desde mediados de la década y de la menor tasa de dependencia económica de los hogares, facilitada por la transición demográfica y el aumento consiguiente de la participación laboral femenina. Las menores oportunidades laborales, los crecientes diferenciales de ingresos laborales por nivel educativo y el crecimiento relativo de los ingresos no salariales fueron, por el contrario, los factores adversos que determinaron el deterioro distributivo en la década de los noventa. Estos efectos predominaron sobre el impacto de tendencias favorables que continuaron, aunque a un ritmo más lento, tales como el aumento y mejor distribución de la educación, los cambios en los patrones demográficos, la mayor participación laboral femenina y la disminución del tamaño medio de los hogares. En las zonas rurales, de acuerdo con este estudio, la apertura comercial destruyó rentas importantes, lo que afectó en forma particularmente severa a los grandes propietarios y a los asalariados de la agricultura comercial, dos grupos que se encuentran en los deciles más altos de la distribución del ingreso rural. El efecto neto fue, por lo tanto, una "nivelación" hacia abajo de los ingresos, que generó una mejor distribución del decreciente ingreso rural.

Los cambios significativos en las tendencias de la distribución de los ingresos laborales en las zonas urbanas se pueden expresar también como resultado de cambios notorios de la rentabilidad de la educación:

\footnotetext{
${ }^{7}$ Existe una discrepancia entre estos estudios en la magnitud de las pérdidas incurridas por el resto de receptores rurales.
}

una tendencia descendente en los años ochenta, sucedida por un aumento importante de la rentabilidad de la educación universitaria en los noventa (Sánchez y Núñez, 1998). De acuerdo con este estudio, estos cambios en los salarios relativos no se deben a modificaciones en la oferta relativa, sino más bien en la demanda laboral, relacionados con los cambios tecnológicos, la estructura de producción sectorial, la productividad relativa de los factores, el proceso de apertura económica y de ajuste de la economía, y el cambio en el precio de los factores no laborales, en especial el precio relativo del capital.

El análisis para el sector rural realizado por Leibovich y Núñez (1999), muestra, para el período 19881995, un mejoramiento en la distribución del ingreso tanto para los asalariados como para los trabajadores por cuenta propia de ambos sexos. En este resultado influyeron positivamente: los cambios en las dotaciones (educación y tamaño del hogar, en particular), en la participación laboral y en la rentabilidad de la educación. También calculan el Gini y medidas entrópicas que muestran que la inequidad es menor para los asalariados que para los trabajadores por cuenta propia, tanto hombres como mujeres. Asimismo, igual que en los estudios para las ciudades, el Gini es mayor para las mujeres que para los hombres.

Una parte importante de los cambios distributivos estuvo asociada a la mayor homogeneidad o heterogeneidad de los ingresos de grupos con iguales características básicas (en términos de edad, género, educación, experiencia, jefatura familiar y residencia, en particular). ${ }^{8}$ De acuerdo con Vélez, Kugler y Bouillon (1999), la mayor homogeneidad de esos ingresos explica una parte importante del mejoramiento en la distribución del ingreso urbano en el período 1978-1988 y la mayor heterogeneidad, la tendencia adversa del período posterior. Para el período reciente, Leibovich y Núñez (1999) encuentran que la mayor homogeneidad de los ingresos de trabajadores con características laborales similares fue uno de los factores determinantes del mejoramiento de la distribución del ingreso rural.

Por su parte, varios estudios han tratado de explorar los efectos de variables macroeconómicas sobre la distribución del ingreso. Bernal, Cárdenas, Sánchez y Núñez (1998) encuentran que un aumento relativo de los sectores transables tiende a reducir el coeficiente de Gini, en tanto que una mayor inflación, una mayor

\footnotetext{
${ }^{8}$ Estos efectos se captan en los residuos (efectos no explicados) en las funciones de generación de ingresos.
} 
tasa de desempleo y una devaluación real tienden a aumentarlo. Aunque los resultados de Ocampo, Pérez, Tovar y Lasso (1998) no corroboran algunos de estos resultados (en particular los efectos distributivos favorables de un menor ritmo de inflación), llegan a conclusiones afines al primero de esos resultados. En particular, este estudio muestra que la apertura comercial tuvo un efecto distributivo adverso, por la vía de mayores diferenciales de ingreso según calificación; el aumento del gasto público en la década de los noventa tuvo un efecto similar. El primero de estos resultados coincide, además, con los obtenidos por Birchenall (1997), quien, utilizando una metodología de funciones de probabilidad, encuentra que la apertura comercial generó un cambio tecnológico que hizo crecer la demanda de mano de obra calificada en las siete ciudades principales. Por su parte, Sánchez y Núñez (1999) encuentran que, a largo plazo, los incrementos en la tasa de desempleo, el tamaño del hogar y la devaluación real aumentan el número de hogares pobres, mientras el mejoramiento de los niveles educativos, productividad y términos del intercambio tiene efectos favorables sobre la incidencia de la pobreza en las ciudades principales.

En síntesis, los estudios existentes asocian en gran medida el deterioro distributivo experimentado en las zonas urbanas de Colombia en los años noventa con un cambio profundo en las remuneraciones laborales por calificación, que ha ensanchado la brecha de ingresos entre trabajadores calificados y no calificados, en favor de los primeros. Las diversas hipótesis han ligado este aumento a la expansión de la demanda relativa de trabajo calificado, resultado de la liberalización comercial, del cambio técnico y del mayor gasto público; este último tiene, sin embargo, un efecto compensatorio favorable en la distribución secundaria del ingreso. Aunque en las áreas rurales hubo un mejoramiento en la distribución, ocurrió en medio de una pérdida significativa de ingresos asociada con un deterioro de los términos de intercambio rurales y la crisis consiguiente de la agricultura comercial.

\section{Ingresos laborales y distribución del ingreso: efectos generales}

El cuadro 10 muestra los resultados de aplicar la metodología de Paes de Barros (2000) a las Encuestas Nacionales de Hogares (ENH), correspondientes a septiembre de 1991 y 1997. La metodología consiste fundamentalmente en simular cuál hubiera sido la distribución del ingreso y la pobreza en 1997 si hubieran prevalecido las condiciones del mercado laboral de 1991. Estas condiciones se refieren a la tasa de participación, la tasa de desempleo, la distribución sectorial del empleo y los ingresos laborales. Las simulaciones se llevan a cabo para los totales nacional, urbano y rural, de dos formas. Por un lado, se analiza el efecto de cada una de las variables del mercado laboral en forma aislada sobre la distribución del ingreso, y por otro, se analiza su efecto conjunto o secuencial. ${ }^{9}$ Con el objetivo de comprobar la solidez de las estima-

CUADRO 10

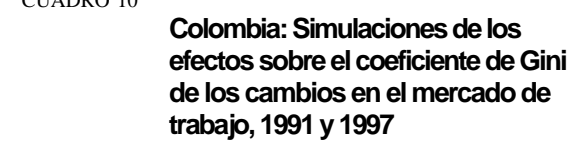

\begin{tabular}{lccc}
\hline & Nacional & Urbano & Rural \\
\hline Gini 1991 & 0.5482 & 0.4977 & 0.4790 \\
Gini 1997 & 0.5650 & 0.5411 & 0.4409 \\
Diferencia & 0.0168 & 0.0434 & -0.0381
\end{tabular}

\begin{tabular}{lccc} 
& \multicolumn{3}{c}{ Participación laboral } \\
Simulado & 0.5595 & 0.5385 & 0.4498 \\
Diferencia & 0.0055 & 0.0026 & -0.0089 \\
$\%$ explicativo & 32.7 & 6.0 & -23.4 \\
& & & \\
& & Desempleo & \\
Simulado & 0.5613 & 0.5365 & 0.4446 \\
Diferencia & 0.0037 & 0.0046 & -0.0037 \\
\% explicativo & 22.1 & 10.7 & -9.8
\end{tabular}

Composición sectorial del empleo

$\begin{array}{lccc}\text { Simulado } & 0.5495 & 0.5314 & 0.4638 \\ \text { Diferencia } & 0.0155 & 0.0097 & -0.0229 \\ \% \text { explicativo } & 92.1 & 22.3 & -60.2\end{array}$

\begin{tabular}{lccc} 
Simulado & 0.5504 & 0.5272 & 0.4295 \\
$\begin{array}{l}\text { Diferencia } \\
\% \text { explicativo }\end{array}$ & 0.0146 & 0.0139 & 0.0114 \\
& 86.5 & 32.0 & 30.0 \\
& & Secuencial & \\
Simulado & 0.5361 & 0.5201 & 0.4376 \\
$\begin{array}{l}\text { Diferencia } \\
\text { \% explicativo }\end{array}$ & 0.0289 & 0.0224 & -0.0414 \\
\hline
\end{tabular}

Fuente: Cálculos propios basados en Encuestas Nacionales de Hogares.

\footnotetext{
${ }^{9}$ La simulación secuencial calcula primero los efectos de cambios de participación; una vez obtenidos estos resultados se hacen las simulaciones de desempleo y sobre esos resultados se hacen las simulaciones de cambios en la estructura sectorial del empleo, para finalmente hacer las simulaciones de salarios sobre esos resultados.
} 
ciones, las simulaciones se repitieron mil veces (experimento Montecarlo).

Las simulaciones de los efectos de cada una de las variables muestran que si las condiciones del mercado laboral de 1991 hubieran prevalecido en 1997, el coeficiente de Gini nacional hubiera sido menor en todos los casos. Así, los cambios en la tasa de participación aumentaron el coeficiente de Gini 0.0055 puntos (de 0.0168 observados), los ocurridos en la tasa de desempleo en 0.0037 , los registrados en la composición sectorial del empleo en 0.0155 y los verificados en los salarios en 0.0146. Los resultados muestran entonces el mayor peso relativo que tuvieron las dos últimas variables sobre la concentración del ingreso que se experimentó durante este período. La simulación secuencial confirma los resultados. Si el conjunto de las condiciones del mercado laboral de 1991 hubiera prevalecido en 1997, el coeficiente de Gini hubiera sido incluso menor que el observado en 1991: 0.536 frente a 0.548 .

Los resultados de las simulaciones para las áreas urbanas de las condiciones del mercado laboral son similares a los encontrados para el total nacional. La transformación de la estructura del empleo y los salarios explica el $22.3 \%$ y el $32.0 \%$ de los cambios en el coeficiente de Gini. Por su parte, la simulación secuencial explica el 52\% del aumento del coeficiente de Gini en las áreas urbanas, es decir, 0.0224 de un incremento total de 0.0434 (de 0.497 a 0.541 ), lo que implica que la mayor concentración del ingreso obedeció también a otros factores no recogidos en las variables del mercado laboral incluidas en las simulaciones (entre las que se encuentran la mayor heterogeneidad de las remuneraciones para trabajadores con iguales características y la evolución de los ingresos no laborales). En las áreas rurales el coeficiente de Gini disminuyó en 0.0381 (de 0.479 a 0.441 ). Los cambios en las tasas de participación, en el desempleo y fundamentalmente en la composición del empleo (que explica el 60\% del cambio del Gini) dan cuenta de buena parte de la disminución de la concentración. Sin embargo, los cambios en los salarios muestran la tendencia contraria.

La misma metodología se aplicó para el caso de los cambios en los niveles de pobreza, con resultados bastante débiles en comparación con los observados en el caso de la distribución del ingreso. De acuerdo con el cuadro 11, el porcentaje de hogares pobres en el total nacional alcanzaba en 1997 el $41.4 \%$ frente al $41.8 \%$ de 1991, es decir, la incidencia de la pobreza era básicamente la misma. Sin embargo, al observar la inci- dencia de la pobreza para las zonas urbanas y rurales se obtienen resultados distintos. Así, el porcentaje de hogares pobres disminuyó en las áreas urbanas de $37.5 \%$ a $28.9 \%$ y aumentó en las rurales de $55.0 \%$ a $59.9 \%$. Los ejercicios de simulación indican que si la tasa de participación, la tasa de desempleo y la composición sectorial del empleo de 1991 hubieran prevalecido en 1997, el porcentaje de pobres urbanos hubiera sido menor al observado. Los resultados de la simulación con la estructura de salarios arrojan resultados en la dirección opuesta.

En el caso del sector urbano, sin embargo, la metodología tiene una capacidad muy limitada para explicar la fuerte reducción en los niveles de pobreza experimentada a lo largo del período analizado, lo que indicaría que existen otros factores que explican esta

CUADRO 11

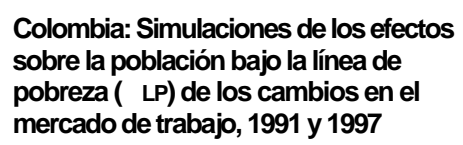

\begin{tabular}{lccc}
\hline & Nacional & Urbano & Rural \\
\hline LP 1991 & 0.4180 & 0.3750 & 0.5500 \\
LP 1997 & 0.4140 & 0.2890 & 0.5990 \\
Diferencia & -0.0040 & -0.0860 & 0.0490
\end{tabular}

\begin{tabular}{|c|c|c|c|}
\hline \multirow[b]{2}{*}{ Simulado } & \multicolumn{3}{|c|}{ Participación laboral } \\
\hline & 0.4081 & 0.2852 & 0.5893 \\
\hline Diferencia & -0.0059 & -0.0038 & -0.0097 \\
\hline \multirow[t]{2}{*}{$\%$ explicativo } & -146.7 & -4.4 & -19.7 \\
\hline & \multicolumn{3}{|c|}{ Desempleo } \\
\hline Simulado & 0.4071 & 0.2824 & 0.5953 \\
\hline Diferencia & -0.0069 & -0.0066 & -0.0037 \\
\hline \multirow[t]{2}{*}{$\%$ explicativo } & -171.6 & -7.6 & 7.6 \\
\hline & \multicolumn{3}{|c|}{ Composición sectorial del empleo } \\
\hline Simulado & 0.3994 & 0.2811 & 0.5697 \\
\hline Diferencia & -0.0146 & -0.0079 & -0.0293 \\
\hline$\%$ explicativo & -365.8 & -9.2 & -59.9 \\
\hline
\end{tabular}

\begin{tabular}{lccc} 
& \multicolumn{3}{c}{ Salarios relativos } \\
Simulado & 0.4156 & 0.2905 & 0.6001 \\
Diferencia & 0.0016 & 0.0015 & 0.0011 \\
\% explicativo & 40.9 & 1.8 & 2.2 \\
& & Secuencial & \\
& & & \\
Simulado & 0.4020 & 0.2839 & 0.5703 \\
Diferencia & -0.0120 & -0.0051 & -0.0287 \\
\% explicativo & -300.1 & -6.0 & -58.6 \\
\hline
\end{tabular}

Fuente: Cálculos propios basados en Encuestas Nacionales de Hogares. 
tendencia. El trabajo de Núñez y Sánchez (1999) muestra que la disminución del porcentaje de pobres en las siete ciudades principales obedeció en lo fundamental a cambios en los precios relativos de la canasta utilizada para medir la línea de pobreza. De los 12 puntos porcentuales en los que disminuyó la pobreza, alrededor de 8.5 puntos son explicados por "efecto precio", esto es, que fue menor la inflación de la canasta de pobreza (alimentos) que la inflación promedio.

La metodología tiene una mejor capacidad para explicar los cambios en la pobreza rural. Así, los resultados de la simulación muestran que si las condiciones del mercado laboral rural de 1991 hubieran prevalecido en 1997, el porcentaje de pobres rurales hubiera sido menor al observado. En particular, la variable con mayor incidencia sobre el aumento del porcentaje de pobre rurales fue la composición del empleo, que explica el $60 \%$ del cambio (0.0293 puntos de 0.0490) en la incidencia de la pobreza. La simulación secuencial, que toma en cuenta el conjunto de las condiciones del mercado laboral prevalecientes en 1991, muestra que estas variables explican en conjunto el 59\% del aumento en la incidencia de la pobreza rural (0.0287 de 0.0490 puntos).

\section{Análisis de los efectos del mercado laboral por deciles de ingreso}

Con el objeto de observar en forma más detallada qué grupos han sido los más afectados por los cambios en el mercado laboral, se han ampliado los ejercicios de simulación a cada uno de los deciles de ingreso, tanto para las áreas urbanas y rurales, de tres variables: ingresos totales per cápita, ingresos laborales per cápita e ingresos de los ocupados. La metodología se aplica para observar solamente el efecto aislado de cada una de las variables del mercado laboral, sin llevar a cabo la llamada simulación secuencial.

Para entender en forma más precisa los resultados de los ejercicios de simulación, en el cuadro 12 se presentan algunas características del mercado laboral por deciles de ingreso total per cápita de los hogares. Como se puede apreciar, las tasas de participación disminuyeron sensiblemente entre 1991 y 1997 en los dos deciles de menores ingresos y, en menor medida, en los deciles 3 a 6 . En contraste, en los deciles superiores de ingreso la tasa de participación laboral de 1997 fue muy similar a la de 1991. Los cambios correspondientes tienen un patrón distinto para las zonas urbanas y rurales. Mientras a nivel urbano la participación laboral cayó en los deciles más pobres y en menor medida en los deciles superiores, la tasa de participación rural aumentó en todos los deciles, principalmente en los más pobres y disminuyó en decil superior de ingresos.

Entre 1991 y 1997 la tasa de desempleo aumentó cerca de tres puntos en el total nacional. Este aumento se concentró en los deciles más pobres de ingresos según se observa en el cuadro 12, tanto en las áreas urbanas como rurales. Entre esos años los ingresos laborales experimentaron un incremento en todos los deciles de ingreso urbano aunque fue mayor en los deciles superiores. Por su parte, los ingresos laborales de las zonas rurales aumentaron para los cuatro prime-

CUADRO 12

Colombia: Indicadores del mercado laboral según deciles de ingreso 1991 y 1997

\begin{tabular}{|c|c|c|c|c|c|c|}
\hline & \multicolumn{2}{|c|}{ Total nacional } & \multicolumn{2}{|c|}{ Urbano } & \multicolumn{2}{|c|}{ Rural } \\
\hline & 1991 & 1997 & 1991 & 1997 & 1991 & 1997 \\
\hline & \multicolumn{6}{|c|}{ Tasa global de participación \% } \\
\hline Decil 1 & 54.7 & 49.2 & 55.5 & 44.7 & 46.4 & 52.9 \\
\hline Decil 2 & 56.5 & 49.3 & 47,3 & 47.5 & 49.9 & 59.1 \\
\hline Decil 3 & 53.1 & 50.1 & 49.8 & 50.5 & 49.6 & 57.7 \\
\hline Decil 4 & 54.2 & 53.2 & 51.8 & 53.6 & 51.0 & 55.5 \\
\hline Decil 5 & 55.7 & 56.4 & 53.9 & 56.3 & 53.7 & 56.6 \\
\hline Decil 6 & 57.1 & 56.6 & 59.3 & 57.4 & 57.6 & 59.2 \\
\hline Decil 7 & 58.9 & 59.1 & 59.0 & 59.1 & 59.4 & 60.5 \\
\hline Decil 8 & 61.8 & 61.0 & 61.8 & 63.0 & 63.1 & 61.5 \\
\hline Decil 9 & 63.8 & 65.2 & 65.7 & 65.9 & 64.2 & 64.8 \\
\hline \multirow[t]{2}{*}{ Decil 10} & 68.9 & 68.4 & 70.9 & 69.9 & 72.2 & 68.6 \\
\hline & \multicolumn{6}{|c|}{ Tasa de desempleo (\%) } \\
\hline Decil 1 & 7.3 & 16.9 & 10.0 & 30.7 & 5.4 & 12.9 \\
\hline Decil 2 & 8.5 & 13.8 & 17.4 & 20.0 & 6.1 & 10.7 \\
\hline Decil 3 & 8.8 & 14.0 & 16.4 & 16.2 & 5.8 & 7.9 \\
\hline Decil 4 & 8.7 & 12.7 & 14.3 & 14.6 & 6.2 & 6.1 \\
\hline Decil 5 . & 9.2 & 11.7 & 11.6 & 11.4 & 4.4 & 6.9 \\
\hline Decil 6 & 8.3 & 10.5 & 10.6 & 10.8 & 3.6 & 5.0 \\
\hline Decil 7 & 7.3 & 9.3 & 9.0 & 8.3 & 5.1 & 5.4 \\
\hline Decil 8 & 6.6 & 7.2 & 6.2 & 6.3 & 4.1 & 5.0 \\
\hline Decil 9 & 5.5 & 6.2 & 5.3 & 6.5 & 2.3 & 4.1 \\
\hline Decil 10 & 4.0 & 4.2 & 3.2 & 3.5 & 1.3 & 2.0 \\
\hline
\end{tabular}

Ingresos laborales anuales per cápita (pesos de 1997)

Decil $1 \quad 53677 \quad 44486 \quad 107299 \quad 136789 \quad 33033 \quad 54196$

$\begin{array}{llllllll}\text { Decil } 2 & 61566 & 92052 & 124861 & 156049 & 42090 & 65726\end{array}$

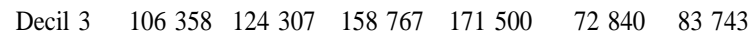

$\begin{array}{lllllllll}\text { Decil } 4 & 130392 & 142 & 184 & 185706 & 196359 & 98 & 041 & 102341\end{array}$

$\begin{array}{lllllllll}\text { Decil } 5 & 149833 & 166767 & 205006 & 207569 & 113091 & 110448\end{array}$

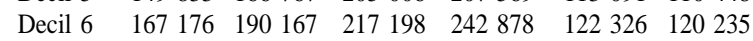

Decil $7 \quad 185970223300 \quad 251955 \quad 263876 \quad 139755 \quad 121570$

$\begin{array}{lllllllll}\text { Decil } 8 & 211027 & 260934 & 286987 & 311433 & 146987 & 132912\end{array}$

Decil $9 \quad 262110 \quad 348211 \quad 371026 \quad 417982 \quad 162367 \quad 150980$

Decil $10 \quad 601382 \quad 850812 \quad 781936 \quad 940018 \quad 186405 \quad 196843$

Fuente: Cálculos propios basados en Encuestas Nacionales de Hogares. 
ros deciles y el decil 10, y disminuyeron para los deciles 5 a 9.

Los efectos de estos cambios del mercado laboral sobre el ingreso total per cápita se presentan en el panel izquierdo del cuadro 13. Ahí se observa que si las tasas de participación laboral de 1991 se hubieran mantenido en 1997, los deciles más pobres, en particular del decil 6 hacia abajo, habrían aumentado su participación en el ingreso total, a su vez mejorando la distribución del ingreso. Esto es consistente con el cuadro 12, que muestra que la participación laboral disminuyó en los deciles más pobres en el período en consideración. Lo mismo ocurre con el efecto simulado de la tasa de desempleo, aunque el mayor efecto sobre el ingreso se habría concentrado en los deciles 2 a 7. Por su parte, el efecto simulado de los cambios en la composición sectorial del empleo aumenta la participación en el ingreso total per cápita de los deciles 5 y 6 , y particularmente del decil 10. Finalmente, el efecto simulado de los salarios muestra que de haber prevalecido en 1997 la estructura salarial nacional de 1991, todos los deciles de ingreso hubieran aumentado su participación en el ingreso total, con excepción del decil más rico, que habría sido el perdedor.

Las simulaciones para las zonas urbanas de los efectos del mercado laboral sobre los cambios en la participación de los distintos deciles confirman los resultados obtenidos en la sección anterior. Si la estructura del mercado laboral de 1991, en cuanto a tasa de participación urbana, tasa de desempleo, composición sectorial del empleo y salarios, se hubiera mantenido en 1997, la participación en el ingreso total de los deciles 6 hacia abajo hubiera sido mayor, lo que hubiera mejorado la distribución del ingreso. Esto concuerda con los resultados del cuadro 12 que muestran que los deciles 6 hacia abajo experimentaron disminuciones en la participación laboral, aumentos en la tasa de desempleo e incrementos de los ingresos laborales en menor proporción que los deciles superiores de ingresos. Sin embargo, se observa que los deciles más favorecidos habrían sido del 3 al 6 , y no los más pobres.

En las zonas rurales, de haber prevalecido la tasa de participación laboral rural de 1991 en 1997 la participación de los ingresos de los deciles 8 hacia abajo habría sido menor, en particular las de los deciles 3 a 7, y habría aumentado la de los deciles 9 y 10, lo que habría implicado un coeficiente de Gini más alto. Un efecto similar al anterior se encuentra al simular el efecto de la tasa de desempleo. La simulación de los efectos de la estructura del empleo y los salarios so- bre los cambios en la participación de cada decil en el ingreso total rural muestra que esa participación habría disminuido para los quintiles más pobres y habría aumentado para los más ricos rurales, lo que habría generado a su vez una mayor concentración del ingreso. En el caso del efecto de la composición sectorial del empleo se observa que estos efectos negativos habrían sido mayores en los deciles 2 a 4 y los positivos se habrían concentrado en los deciles 8 a 10. En el caso del efecto de los salarios, la simulación muestra que todos los deciles habrían perdido participación en el ingreso con excepción del decil más rico. Los resultados confirman la evolución del mercado laboral rural entre 1991 y 1997, que muestra aumentos de la participación laboral y el desempleo relativamente mayores en los deciles de ingresos más pobres, como también incrementos en los ingresos laborales para los deciles 5 hacia abajo y 10, y caídas para los deciles 6 a 9 .

El panel central del cuadro 13 contiene el mismo conjunto de simulaciones descrito anteriormente pero hechas sobre el ingreso laboral per cápita en vez del ingreso total. El efecto simulado de la tasa de participación y de la tasa de desempleo sobre los cambios en la participación de los distintos deciles en el ingreso laboral muestra resultados similares a los obtenidos en el caso del ingreso total, aunque de magnitudes generalmente menores, en particular los de la simulación de los efectos de la tasa de desempleo. En contraste, los efectos simulados de la composición del empleo y la evolución de los salarios son de mayor magnitud. Así, el cuadro muestra que la participación en el ingreso laboral de todos los deciles, tanto para el total nacional como para las zonas urbanas, habría sido mayor a la observada, con excepción del quintil más rico (en magnitudes pequeñas en el caso del decil 9 en las zonas urbanas). Para las zonas rurales, los efectos de la composición del empleo y de la estructura salarial sobre la participación en el ingreso rural son también de mayor magnitud a la observada para el caso de los ingresos totales. La participación en el ingreso laboral habría caído para todos los deciles y habría aumentado significativamente para el decil más rico.

Por su parte, las simulaciones de los efectos del mercado laboral sobre la participación en los ingresos de los distintos deciles de ocupados, presentadas en el panel derecho del cuadro 13, muestran, para el total nacional y las zonas urbanas resultados muy similares a los obtenidos para el caso de los ingresos laborales per cápita (panel central del cuadro) pero naturalmente mucho más intensos en el caso del desempleo. No ocurre, sin embargo, lo mismo en las zonas rurales. En 
CUADRO 13

Colombia: Cambio de la participación en los ingresos totales per cápita, en el ingreso laboral per cápita de los hogares y en el ingreso de los ocupados. Simulaciones de los cambios en el mercado de trabajo, 1991-1997 (Porcentajes)

\begin{tabular}{|c|c|c|c|c|c|c|c|c|c|}
\hline & \multicolumn{3}{|c|}{$\begin{array}{l}\text { Cambio de la participación en el } \\
\text { ingreso total per cápita de los hogares }\end{array}$} & \multicolumn{3}{|c|}{$\begin{array}{l}\text { Cambio de la participación en el } \\
\text { ingreso laboral per cápita de los hogares }\end{array}$} & \multicolumn{3}{|c|}{$\begin{array}{l}\text { Cambio de la participación en el } \\
\text { ingreso de los ocupados }\end{array}$} \\
\hline & Nacional & Urbano & Rural & Nacional & Urbano & Rural & Nacional & Urbano & Rural \\
\hline \multicolumn{10}{|c|}{ Participación laboral } \\
\hline Decil 1 & 0.05 & 0.01 & -0.03 & 0.01 & 0.03 & -0.01 & 0.06 & 0.03 & 0.04 \\
\hline Decil 2 & 0.06 & 0.02 & -0.07 & 0.03 & 0.04 & -0.02 & 0.08 & 0.06 & 0.17 \\
\hline Decil 3 & 0.05 & 0.05 & -0.09 & 0.02 & 0.03 & -0.03 & 0.11 & 0.07 & 0.13 \\
\hline Decil 4 & 0.08 & 0.04 & -0.11 & 0.01 & 0.06 & -0.03 & 0.11 & 0.01 & -0.01 \\
\hline Decil 5 & 0.06 & 0.04 & -0.11 & 0.04 & 0.06 & -0.05 & 0.06 & 0.01 & 0.04 \\
\hline Decil 6 & 0.04 & 0.03 & -0.10 & 0.05 & 0.04 & -0.07 & 0.10 & 0.19 & 0.08 \\
\hline Decil 7 & 0.00 & 0.00 & -0.11 & 0.04 & 0.04 & -0.02 & 0.22 & 0.05 & -0.10 \\
\hline Decil 8 & -0.02 & 0.00 & -0.01 & 0.02 & 0.04 & -0.02 & 0.09 & 0.06 & -0.07 \\
\hline Decil 9 & -0.04 & -0.04 & 0.19 & 0.01 & 0.04 & -0.03 & -0.02 & -0.02 & 0.40 \\
\hline Decil 10 & -0.27 & -0.16 & 0.45 & -0.24 & -0.39 & 0.29 & -0.83 & -0.47 & -0.69 \\
\hline \multicolumn{10}{|c|}{ Desempleo } \\
\hline Decil 1 & 0.04 & 0.01 & -0.03 & 0.00 & 0.01 & 0.00 & 0.07 & 0.07 & 0.06 \\
\hline Decil 2 & 0.07 & 0.02 & -0.07 & -0.01 & 0.01 & -0.01 & 0.12 & 0.11 & 0.12 \\
\hline Decil 3 & 0.08 & 0.04 & -0.09 & 0.00 & 0.02 & -0.02 & 0.14 & 0.16 & 0.18 \\
\hline Decil 4 & 0.08 & 0.06 & -0.09 & 0.00 & 0.01 & -0.03 & 0.18 & 0.15 & 0.20 \\
\hline Decil 5 & 0.09 & 0.05 & -0.13 & 0.01 & 0.00 & -0.01 & 0.18 & 0.20 & 0.18 \\
\hline Decil 6 & 0.05 & 0.05 & -0.11 & 0.01 & 0.03 & -0.02 & 0.22 & 0.19 & 0.22 \\
\hline Decil 7 & 0.03 & 0.03 & -0.10 & 0.02 & 0.00 & 0.00 & 0.18 & 0.20 & 0.21 \\
\hline Decil 8 & -0.04 & 0.02 & -0.01 & 0.00 & 0.02 & 0.05 & 0.18 & 0.15 & 0.07 \\
\hline Decil 9 & -0.07 & -0.02 & 0.17 & -0.02 & -0.03 & 0.06 & 0.10 & 0.03 & 0.09 \\
\hline Decil 10 & -0.33 & -0.27 & 0.48 & -0.01 & -0.08 & -0.03 & -1.37 & -1.25 & -1.33 \\
\hline \multicolumn{10}{|c|}{ Composición sectorial del empleo } \\
\hline Decil 1 & -0.02 & 0.00 & -0.03 & 0.13 & 0.05 & -0.17 & 0.07 & 0.08 & 0.05 \\
\hline Decil 2 & -0.05 & 0.00 & -0.08 & 0.16 & 0.05 & -0.37 & 0.14 & 0.13 & 0.16 \\
\hline Docii 3 & -0.02 & -0.03 & -0.09 & 0.14 & 0.09 & -0.37 & 0.17 & 0.17 & 0.18 \\
\hline Decil 4 & -0.08 & 0.02 & -0.13 & 0.16 & 0.08 & -0.33 & 0.20 & 0.21 & 0.21 \\
\hline Decil 5 & 0.05 & 0.03 & -0.04 & 0.16 & 0.12 & -0.32 & 0.24 & 0.19 & 0.23 \\
\hline Decil 6 & 0.07 & -0.04 & -0.05 & 0.18 & 0.09 & -0.23 & 0.22 & 0.26 & 0.25 \\
\hline Decil 7 & -0.08 & -0.04 & -0.03 & 0.15 & 0.10 & -0.24 & 0.28 & 0.25 & 0.18 \\
\hline Decil 8 & -0.04 & -0.04 & 0.17 & 0.15 & 0.09 & -0.30 & 0.26 & 0.21 & 0.12 \\
\hline Decil 9 & -0.06 & -0.07 & 0.14 & 0.08 & 0.05 & -0.14 & 0.05 & 0.02 & 0.07 \\
\hline Decil 10 & 0.22 & 0.16 & 0.14 & -1.30 & -0.72 & 2.47 & -1.63 & -1.53 & -1.45 \\
\hline \multicolumn{10}{|c|}{ Salarios relativos } \\
\hline Decil 1 & 0.02 & 0.03 & -0.02 & 0.13 & 0.05 & -0.17 & 0.07 & 0.02 & 0.09 \\
\hline Decil 2 & 0.03 & 0.02 & -0.03 & 0.19 & 0.07 & -0.39 & 0.11 & 0.11 & 0.20 \\
\hline Decil 3 & 0.01 & 0.04 & -0.05 & 0.18 & 0.08 & -0.42 & 0.19 & 0.13 & 0.19 \\
\hline Decil 4 & 0.03 & 0.04 & -0.03 & 0.16 & 0.09 & -0.33 & 0.17 & 0.19 & 0.20 \\
\hline Decil 5 & 0.05 & 0.05 & -0.05 & 0.19 & 0.10 & -0.36 & 0.22 & 0.26 & 0.27 \\
\hline Decil 6 & 0.05 & 0.05 & -0.03 & 0.17 & 0.13 & -0.28 & 0.32 & 0.32 & 0.29 \\
\hline Decil 7 & 0.04 & 0.06 & -0.03 & 0.20 & 0.12 & -0.22 & 0.26 & 0.23 & 0.03 \\
\hline Decil 8 & 0.02 & 0.07 & -0.05 & 0.18 & 0.10 & -0.36 & 0.17 & 0.13 & 0.22 \\
\hline Decil 9 & 0.01 & 0.03 & -0.06 & 0.06 & -0.02 & -0.23 & -0.12 & -0.13 & 0.15 \\
\hline Decil 10 & -0.28 & -0.38 & 0.37 & -1.47 & -0.73 & 2.77 & -1.40 & -1.27 & -1.65 \\
\hline
\end{tabular}

Fuente: Cálculos propios basados en Encuestas Nacionales de Hogares. 
particular, los efectos del mercado de trabajo sobre los distintos receptores de ingreso tendrían el mismo signo en las zonas urbanas y rurales, y no el signo opuesto, como acontece en las simulaciones alternativas. Un

\section{VI}

\section{Conclusiones}

Este trabajo analizó los cambios experimentados por el mercado laboral y la distribución del ingreso durante el período comprendido entre la iniciación de las reformas en 1991 y 1997. El crecimiento económico estuvo determinado durante estos años por los fuertes giros que experimentó la demanda agregada interna. A su vez, la estructura productiva sufrió cambios apreciables: aumentó el peso relativo de los sectores productores de bienes y servicios no comercializables internacionalmente, al tiempo que se produjo un marcado deterioro de los sectores transables, especialmente la agricultura y la industria.

Las repercusiones de estos cambios en el mercado laboral fueron significativas. La capacidad de la economía para generar empleo se deterioró notablemente. Éste no es, por lo demás, un fenómeno reciente, ya que comenzó a manifestarse durante el auge espectacular de la demanda agregada en 1992-1995, pero entonces no se reflejó sobre la tasa de desempleo, dada la tendencia favorable de la participación laboral. Por sectores, el deterioro de la capacidad de generación de empleo en la agricultura fue notable a comienzos de la década, y en la industria a partir de su desaceleración a mediados de ella. Este comportamiento fue compensado durante la fase de auge de la primera mitad de los años noventa por la respuesta positiva de las actividades no transables, pero este efecto favorable desapareció cuando se agotó el auge de la demanda interna a mediados de la década.

La desfavorable evolución del empleo ha afectado fundamentalmente a los trabajadores de más bajo nivel educativo. Los cambios en la estructura productiva han golpeado, en efecto, a los trabajadores con menos educación, ya que la eliminación de empleo en los sectores transables afectó más a estos trabajadores, entendimiento mucho más preciso de por qué se observan esos efectos contrarios requeriría un estudio en detalle de los cambios acontecidos en la estructura de los hogares rurales durante la década de los noventa. en tanto que el aumento de empleo en los sectores no transables tendió a favorecer a trabajadores con mayores niveles educativos. Por otra parte, el cambio tecnológico ha sido de uso intensivo de capital y ahorrador de mano de obra en todos los niveles educativos, aunque con mayor incidencia en la mano de obra de menor calificación. Los sesgos generados por la apertura económica hacia la demanda de mano de obra más instruida se reflejan también en la mayor rentabilidad de la educación para los niveles de escolaridad más altos y en el incremento de los ingresos relativos de estos trabajadores, que ha presionado adversamente la distribución urbana de ingresos.

Entre 1991 y 1997 el país experimentó un aumento en la concentración del ingreso medida con el coeficiente de Gini, aunque como resultado de tendencias opuestas en las zonas urbanas y rurales. Al simular los efectos de los cambios en el mercado laboral entre 1991 y 1997 sobre la distribución del ingreso se observa que los efectos más significativos para el total nacional se dieron a través de la composición sectorial del empleo y la estructura de los salarios y en menor grado a través de los cambios en las tasas de participación laboral y desempleo. Los mismos resultados se obtienen para las zonas urbanas. Las simulaciones para las zonas rurales muestran que los cambios en el mercado laboral ocurridos entre 1991 y 1997, en particular las modificaciones en la estructura del empleo, contribuyeron a disminuir la concentración del ingreso. La evolución de la pobreza y, en particular, su fuerte reducción en las zonas urbanas entre 1991 y 1997, estuvo dominada por otros efectos, en especial por la disminución significativa en el costo de la canasta de alimentos, que tuvo, como es obvio, signos opuestos en términos de ingresos en las zonas urbanas y rurales. 


\section{Bibliografía}

Birchenall, J. (1997): Income Distribution, Human Capital and Economic Growth in Colombia, Archivos de macroeconomía, $\mathrm{N}^{\circ} 70$, Santafé de Bogotá, Colombia, Departamento Nacional de Planeación, Unidad de Análisis Macroeconómico.

Bernal, R., M. Cárdenas, F. Sánchez y J. Núñez (eds.), La distribución del ingreso en Colombia: tendencias recientes y retos de la política pública, Santafé de Bogotá, Tercer Mundo Editores.

Colombia, Contraloría General de la República (1986): El problema laboral colombiano: diagnóstico, perspectivas y políticas. Informe final de la Misión de Empleo, Economía colombiana, $\mathrm{N}^{\circ} 10$, Santafé de Bogotá.

Colombia, DANE (Departamento Administrativo Nacional de Estadística) (1999): Evolución de la economía colombiana. Primer trimestre de 1999, Santafé de Bogotá.

Colombia, DNP/PNUD (Departamento Nacional de Planeación/Programa de las Naciones Unidas para el Desarrollo) (1998): Informe de desarrollo humano para Colombia, 1998, Santafé de Bogotá, Tercer Mundo Editores.

Farné, S., A. Vivas y J. Núñez (1998): La estabilidad laboral en el mercado de trabajo urbano en Colombia, 1984-1986, Santafé de Bogotá.

Henao, M.L. y A. Parra (1998): Educación y mercados de trabajo, Empleo: un desafío para Colombia, Santafé de Bogotá, Organización Internacional del Trabajo (OIT).

Leibovich, J. y J. Núñez (1999): The Microeconomics of Income Distribution Dynamics in Rural Colombia (1978-1988-1995), Documento CEDE, $\mathrm{N}^{\circ} 12$, Santafé de Bogotá, Centro de Estudios sobre Desarrollo Económico (CEDE), agosto.

Núñez, J. y F. Sánchez (1999): Estimaciones trimestrales de la línea de pobreza y sus relaciones con el desempeño macroeconómico colombiano (1977-1997), Archivos de macroecono-

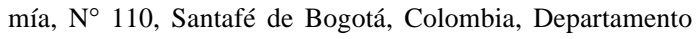
Nacional de Planeación, Unidad de Análisis Macroeconómico.

Ocampo, J. A. (1997): Una evaluación de la situación fiscal colombiana, Coyuntura económica, vol. XXVII, $N^{\circ} 2$, Santafé de Bogotá, Fundación para la Educación Superior y el Desarrollo (FEDESARROLLO), junio.

(1998): Una década de grandes transformaciones económicas (1986-1996), Nueva historia de Colombia, vol. VIII, Santafé de Bogotá, Editorial Planeta.

Ocampo, J. A.; M. J. Pérez; C. Tovar y F. J. Lasso (1998): Macroeconomía, ajuste estructural y equidad en Colombia: 19781996, E. Ganuza, L. Taylor y S. Morley (eds.), Política macroeconómica para América Latina y el Caribe, Madrid, Mundi Prensa.

Ocampo, J. A. y C. Tovar (1999): Price-Based Capital Account Regulations: The Colombian Experience, serie Financiamiento del Desarrollo, N 87, Santiago de Chile, Comisión Económica para América Latina y el Caribe (CEPAL).

OIT (Oficina Internacional del Trabajo) (1998): Empleo: un desafío para Colombia, Santafé de Bogotá, Proyecto OIT/Ministerio de Trabajo.

Paes de Barros, R. (2000): Methodological issues, trabajo presentado al proyecto Liberalización de la balanza de pagos: efectos sobre el empleo, la distribución, la pobreza y el crecimiento, Buenos Aires, febrero.

Reina, M. y D. Yanovich (1998): Salud, educación y desempleo: diagnóstico y recomendaciones, Cuadernos, $\mathrm{N}^{\circ} 4$, Santafé de Bogotá, FEDESARROLLO.

Ribero, R. y J. García (1996): Estadísticas descriptivas del mercado laboral masculino y femenino en Colombia: 1976-1995, Archivos de macroeconomía, $N^{\circ} 48$, Santafé de Bogotá, Colombia, Departamento Nacional de Planeación, Unidad de Análisis Macroeconómico.

Sánchez, F. (ed.) (1998): La distribución del ingreso en Colombia: tendencias recientes y retos de la política pública, Santafé de Bogotá, Tercer Mundo Editores.

Sánchez, F. y J. Núñez (1998): Educación y salarios relativos en Colombia, 1976-1995. Determinantes, evolución e implicaciones para la distribución del ingreso, F. Sánchez (ed.), La distribución del ingreso en Colombia: tendencias recientes y retos de la política pública, Santafé de Bogotá, Tercer Mundo Editores.

(1999): Descentralización, pobreza y acceso a los servicios sociales, ¿Quién se benefició del gasto público en los noventa?, Coyuntura social, $\mathrm{N}^{\circ} 20$, Santafé de Bogotá, FEDESARROLLO.

Taylor, L. (1998): Balance of payments liberalization: Effects on employment, distribution, poverty and growth, Términos de referencia para el proyecto Liberalización de la balanza de pagos: efectos sobre el empleo, la distribución, la pobreza y el crecimiento, Santiago de Chile, Programa de las Naciones Unidas para el Desarrollo (PNUD)/CEPAL/Banco Interamericano de Desarrollo (BID).

Vélez, C. E., A. Kugler y C. Bouillón (1999): The reversal of inequality gains in urban Colombia, 1978-1995: a combination of persistent and fluctuation forces, Washington, D.C., Banco Mundial, mimeo.

Villar, L. y H. Rincón (2000): The Colombian economy in the nineties: capital flows and foreign exchange regimes, trabajo presentado a la conferencia Critical Issues in Financial Reform: Latin America/Caribbean and Canadian perspectives, Toronto, Universidad de Toronto, The Munk Centre for International Studies Programme on Latin America and the Caribbean, junio. 